\title{
Quantile-dependent expressivity of serum C-reactive protein concentrations in family sets
}

\author{
Paul T Williams ${ }^{\text {Corresp. } 1}$ \\ ${ }^{1}$ Molecular Biophysics \& Integrated Bioimaging Division, Lawrence Berkeley National Laboratory, Berkeley, California, USA \\ Corresponding Author: Paul T Williams \\ Email address: 1742spyglass@comcast.net
}

Background: "Quantile-dependent expressivity" occurs when the effect size of a genetic variant depends upon whether the phenotype (e.g. C-reactive protein, CRP) is high or low relative to its distribution. We have previously shown that the heritabilities $\left(h^{2}\right)$ of coffee and alcohol consumption, postprandial lipemia, lipoproteins, leptin, adiponectin, adiposity, and pulmonary function are quantilespecific. Whether CRP heritability is quantile-specific is currently unknown.

Methods: Serum CRP concentrations from 2036 sibships and 6144 offspring-parent pairs were analyzed from the Framingham Heart Study. Quantile-specific heritability from full-sib $\left(\beta_{\mathrm{Fs}}\right.$, $\left.h^{2}=\left\{\left(1+8 r_{\text {spouse }} \beta_{\mathrm{Fs}}\right)^{0.5}-1\right\} /\left(2 r_{\text {spouse }}\right)\right)$ and offspring-parent regression slopes $\left(\beta_{\text {op }}, h^{2}=2 \beta_{\text {op }} /\left(1+r_{\text {spouse }}\right)\right)$ were estimated robustly by quantile regression with nonparametric significance determined from 1000 bootstrap samples.

Results: Quantile-specific $h^{2}( \pm \mathrm{SE})$ increased with increasing percentiles of the offspring's age- and sexadjusted CRP distribution when estimated from $\beta_{\text {op }}\left(P_{\text {trend }}=0.0004\right): 0.02 \pm 0.01$ at the $10^{\text {th }}, 0.04 \pm 0.01$ at the $25^{\text {th }}, 0.10 \pm 0.02$ at the $50^{\text {th }}, 0.20 \pm 0.05$ at the $75^{\text {th }}$, and $0.33 \pm 0.10$ at the $90^{\text {th }}$ percentile, and when estimated from $\beta_{\mathrm{FS}}\left(P_{\text {trend }}=0.0008\right): 0.03 \pm 0.01$ at the $10^{\text {th }}, 0.06 \pm 0.02$ at the $25^{\text {th }}, 0.14 \pm 0.03$ at the $50^{\text {th }}$, $0.24 \pm 0.05$ at the $75^{\text {th }}$, and $0.53 \pm 0.21$ at the $90^{\text {th }}$ percentile.

Conclusion: Heritability of serum CRP concentration is quantile-specific, which may explain or contribute to the inflated CRP differences between CRP (rs1130864, rs1205, rs1800947, rs2794521, rs3091244), FGB (rs1800787), IL-6 (rs1800795, rs1800796), IL6R (rs8192284), TNF- $\alpha$ (rs1800629) and APOE genotypes following CABG surgery, stroke, TIA, curative esophagectomy, intensive periodontal therapy, or acute exercise; during acute coronary syndrome or Staphylococcus aureus bacteremia; or in patients with chronic rheumatoid arthritis, diabetes, peripheral arterial disease, ankylosing spondylitis, obesity or inflammatory bowel disease or who smoke. 
1 Quantile-dependent expressivity of serum C-reactive protein concentrations in family sets.

2

3 Paul T Williams, $\mathrm{PhD}$

4 Lawrence Berkeley National Laboratory

5 Molecular Biophysics \& Integrated Bioimaging Division

61 Cyclotron Road

7 Berkeley, CA 94720

8

9 Running title: Quantile-specific CRP heritability

10

11

12 Complete address of corresponding author and to whom correspondence should be addressed:

13

14 Paul T Williams

15 Molecular Biophysics \& Integrated Bioimaging Division

16 Lawrence Berkeley National Laboratory

17 Berkeley, California USA

18 Email. ptwilliams@,1bl.gov

19

20 
22 Abbreviation key

23

24 AFT3 Activating transcription factor

25 APOA2 Apolipoprotein A2

26 APOE Apolipoprotein E

$27 \beta_{\mathrm{FS}}$

Full-sib regression slope

$28 \beta_{\mathrm{OP}}$

Offspring-parent regression slope

29 BMI

Body mass index

30 CABG

Coronary Artery Bypass surgery

31 CHD

Coronary Heart Disease

32 CLOCK

Circadian locomotor output cycles kaput

33 CRP

C-reactive protein

34 ESR

Erythrocyte sedimentation rate

$35 F G B$

Fibrinogen beta-chain

$36 h^{2}$

Heritability in the narrow sense

37 HNF1A

hepatic nuclear factor- $1 \alpha$

$38 \quad I L-6$

Interleukin-6

39 IL6R

Interleukin-6 receptor

40 IBD

Inflammatory bowel disease

41 MI

Myocardial infarction

42 NHLBI

National Heart Lung and Blood Institute

43 NS

Not statistically significant $(\mathrm{P}>0.05)$

44 PAD

Peripheral arterial disease

45 RANK

Receptor activator of nuclear factor $\kappa \mathrm{B}$

46 RANKL Receptor activator of nuclear factor $\kappa \mathrm{B}$ ligand

47 SD

Standard deviation

48 SE

Standard error

49 SNP

Single nucleotide polymorphism

50 TIA

Transient Ischemic Attack

$51 \quad T N F-\alpha$

Tumor necrosis factor $\alpha$

52 T2DM

Type 2 diabetes mellitus 
54

55

Abstract

56

57 Background: "Quantile-dependent expressivity" occurs when the effect size of a genetic variant 58 depends upon whether the phenotype (e.g. C-reactive protein, CRP) is high or low relative to its 59 distribution. We have previously shown that the heritabilities $\left(h^{2}\right)$ of coffee and alcohol 60 consumption, postprandial lipemia, lipoproteins, leptin, adiponectin, adiposity, and pulmonary

61 function are quantile-specific. Whether CRP heritability is quantile-specific is currently 62 unknown.

63 Methods Serum CRP concentrations from 2036 sibships and 6144 offspring-parent pairs were 64 analyzed from the Framingham Heart Study. Quantile-specific heritability from full-sib ( $\beta_{\mathrm{FS}}$, $\left.65 h^{2}=\left\{\left(1+8 \mathrm{r}_{\text {spouse }} \beta_{\mathrm{FS}}\right)^{0.5}-1\right\} /\left(2 \mathrm{r}_{\text {spouse }}\right)\right)$ and offspring-parent regression slopes $\left(\beta_{\mathrm{OP}}\right.$, $\left.66 h^{2}=2 \beta_{\mathrm{OP}} /\left(1+\mathrm{r}_{\text {spouse }}\right)\right)$ were estimated robustly by quantile regression with nonparametric 67 significance determined from 1000 bootstrap samples.

68 Results: Quantile-specific $h^{2}( \pm \mathrm{SE})$ increased with increasing percentiles of the offspring's age69 and sex-adjusted CRP distribution when estimated from $\beta_{\mathrm{OP}}\left(\mathrm{P}_{\text {trend }}=0.0004\right): 0.02 \pm 0.01$ at the $10^{\text {th }}, 0.04 \pm 0.01$ at the $25^{\text {th }}, 0.10 \pm 0.02$ at the $50^{\text {th }}, 0.20 \pm 0.05$ at the $75^{\text {th }}$, and $0.33 \pm 0.10$ at the $90^{\text {th }}$

71 percentile, and when estimated from $\beta_{\mathrm{FS}}\left(\mathrm{P}_{\text {trend }}=0.0008\right): 0.03 \pm 0.01$ at the $10^{\text {th }}, 0.06 \pm 0.02$ at the $7225^{\text {th }}, 0.14 \pm 0.03$ at the $50^{\text {th }}, 0.24 \pm 0.05$ at the $75^{\text {th }}$, and $0.53 \pm 0.21$ at the $90^{\text {th }}$ percentile.

73 Conclusion: Heritability of serum CRP concentration is quantile-specific, which may explain or 74 contribute to the inflated CRP differences between CRP (rs1130864, rs1205, rs 1800947, 75 rs2794521, rs3091244), FGB (rs1800787), IL-6 (rs1800795, rs 1800796), IL6R (rs8192284), $T N F-\alpha($ rs 1800629$)$ and $A P O E$ genotypes following CABG surgery, stroke, TIA, curative esophagectomy, intensive periodontal therapy, or acute exercise; during acute coronary 79 80 syndrome or Staphylococcus aureus bacteremia; or in patients with chronic rheumatoid arthritis, diabetes, peripheral arterial disease, ankylosing spondylitis, obesity or inflammatory bowel 81 82 
86 C-reactive protein (CRP) concentrations are reflective of low-grade systemic inflammation.

87 Higher basal concentrations are associated with increasing age, obesity, smoking, disease

88 (Alzheimer's, cardiovascular, Type 2 diabetes mellitus (T2DM)) and female sex [1].

89 Prospectively, plasma CRP-concentrations predict de novo atherothrombotic cardiovascular 90 events [2]. Basal CRP concentrations are also in part genetic, with an estimated heritability of

91 about $35 \%$, but with individual estimates varying greatly [3]. CRP concentration may increase by 92500 -fold following an acute-phase stimulus due to enhanced hepatic transcription, primarily in 93 response to the proinflammatory cytokine interleukin 6 [4,5]. Clinically, CRP concentrations are

94 used for the diagnosis and monitoring of inflammatory processes [4] in rheumatologic disease $95[6,7,8]$, ankylosing spondylitis [9], inflammatory bowel disease [10], pancreatitis [1], 96 cardiovascular disease [5,11], cancer [1], and other infections [4].

97

98

99

100

101

102

103

104

105

106

107

108

109

110

111

112

113
"Quantile-dependent expressivity" postulates that the effects of genetic variants on phenotypes may depend on the whether the phenotype (e.g., CRP concentration) is high or low relative to its distribution. The heritability of adiposity [12,13]; plasma concentrations of triglyceride [12,14], high-density lipoproteins [12,15,16], total cholesterol [17], leptin [18], and adiponection [19]; pulmonary function [20]; and intakes of alcohol [21] and coffee [22] are quantile dependent, whereas height and the intakes of other macronutrients are not [12,13,21]. Others have also demonstrated increasing genetic effect size with increasing BMI levels [23-26]. A particularly compelling case for quantile-dependent expressivity is the linear increases in the effect sizes of single nucleotide polymorphisms (SNP) with postprandial increases in triglyceride [27] and adiponectin [19] concentrations during lipemia-compelling because their concordant increases are demonstrable within individuals and within hours, exclusive of other sources of temporal and between-subject variation. Many purported examples of gene-environment interactions may be attributable to quantile-dependent expressivity when subjects are selected for conditions that distinguish high vs. low phenotype values [16]. With respect to precision-medicine, genetic markers for identifying patients most likely to benefit from medications or diet may also be artifacts of quantile-dependent expressivity when the markers simply track the change

Peer) reviewing PDF | (2020:10:53970:1:1:CHECK 8 Jan 2021) 
114 heritability associated with drug-, diet-, or behavior-induced changes in the average phenotype 115 value $[14,15,17,27]$.

116

117 It is not known whether CRP heritability is quantile specific or whether the CRP gene-

118 environment interactions reported by others are consistent with quantile-dependent expressivity.

119 Therefore, quantile-dependent expressivity of CRP was investigated by applying quantile

120 regression [28,29] to sibships and offspring-parent pairs from the Framingham Study [30,31] to

121 estimate heritability in the narrow sense ( $h^{2}$ [32]) at different quantile of the CRP distributions.

122 Heritability of untransformed CRP concentrations was studied because only a small proportion

123 of CRP variation is attributable to specific SNPs [33], because quantile regression does not

124 require statistical normality [28,29], and because no biological justification for logarithmic

125 transforming CRP concentrations has heretofore been provided. The discussion furthers this

126 investigation by re-examining published examples of CRP gene-environment interactions from

127 the perspective of quantile-dependent expressivity. Of particular interest are the effects of

128 genetic variants on CRP concentrations during its acute phase response to infections, trauma, and

129 surgery because these may exceed basal CRP levels by over 100-fold [4,34,35]. Quantile-

130 dependent expressivity hypothesizes that genetic effects on CRP concentrations should increase

131 in accordance with changing CRP concentrations during intermediate and peak increases in it's

132 acute phase concentrations.

133

134

135

Methods

136

137 The Framingham Study data were obtained from the National Institutes of Health

138 FRAMCOHORT, GEN3, FRAMOFFSPRING Research Materials obtained from the National

139 Heart, lung, and Blood (NHLBI) Biologic Specimen and Data Repository Information

140 Coordinating Center. The hypothesis tested not considered as part of the initial Framingham

141 Study design and is exploratory. The Framingham Heart Study included three cohorts. The

142 Original Cohort includes 5209 thirty to fifty-nine year old men and women who lived in

143 Framingham, Massachusetts. The Offspring Cohort is made up of the 5,124 adult children of the

144 Original Cohort and their spouses. They were initially examined between 1971 and 1975, 
145 reexamined eight years later, and then every three to four years thereafter [30]. The Third

146 Generation Cohort is the children of the Offspring Cohort [31]. Subjects used in the current

147 analyses were at least 16 years of age and were self-identified as non-Hispanic white.

148 Phlebotomy was performed on fasting participants who had rested for 5 to 10 minutes in a supine

149 position, typically between 8 and $9 \mathrm{AM}$. Specimens were stored at $-80^{\circ} \mathrm{C}$ without freeze-thaw

150 cycles until assay. Serum high-sensitivity CRP concentrations were measured with a Dade

151 Behring BN100 nephelometer (Deerfield, IL) with a Kappa statistic of 0.95 for 146 samples run

152 in duplicate [36]. Plasma CRP concentrations were measured for examinations 2, 6, 7, 8, and 9

153 of the Offspring Cohort, and examinations 1 and 2 of the Third Generation Cohort.

154

155 Our analyses of these data were approved by Lawrence Berkeley National Laboratory Human

156 Subjects Committee (HSC) for protocol "Gene-environment interaction vs. quantile-dependent

157 penetrance of established SNPs (107H021)" LBNL holds Office of Human Research Protections

158 Federal wide Assurance number FWA 00006253. Approval number: 107H021-13MR20. Signed

159 informed consent were obtained from all participants or parent and/or legal guardian if $<18$ years

160 of age. All surveys were conducted under the guidelines set forth by the Framingham Heart

161 Study human use committee.

162

163 Statistics. The statistical methodology has been described in detail elsewhere [12-22,27] and is

164 summarized here briefly for completeness. The only eligibility requirement for inclusion in the

165 analyses was CPR values for offspring, parents and siblings. Standard least-squares regression

166 was used for sex and age adjustment separately in each cohort using with female $(0,1)$, age, age ${ }^{2}$,

167 female $\mathrm{x}$ age, and female $\mathrm{x} \mathrm{age}^{2}$ as independent variables. Individual subject values were taken

168 as the average over all available exams of the age and sex-adjusted concentrations. Parents from

169 the Offspring Cohort and their children from the Third Generation Cohort were used to compute

170 offspring-parent regression slopes $\left(\beta_{\mathrm{OP}}\right)$. Siblings were obtained from the Third Generation and

171 Offspring Cohorts. Full-sibling regression slopes $\left(\beta_{\mathrm{FS}}\right)$ were calculated by forming all $\mathrm{k}_{\mathrm{i}}\left(\mathrm{k}_{\mathrm{i}}-1\right)$

172 sibpair combinations for the $\mathrm{k}_{\mathrm{i}}$ siblings within sibship $\mathrm{i}$ and assigning equal weight to each

173 sibling [37].

174

Peer] reviewing PDF | (2020:10:53970:1:1:CHECK 8 Jan 2021) 
175 The sqreg command of Stata (version. 11, StataCorp, College Station, TX) was used to perform

176 simultaneous quantile regression. The variance-covariance matrix for the ninety-one quantile

177 regression coefficients between the 5th and 95th percentiles of the offspring's distribution was

178 estimated from 1000 bootstrap samples [29]. The test and lincom post-estimation procedures

179 were used to test linear combinations of the slopes with $\Sigma\left(\mathrm{k}_{\mathrm{i}}-1\right)$ degrees of freedom for sibship

180 regression slopes and $\Sigma \mathrm{k}_{\mathrm{i}}$-2 degrees of freedom for offspring-parent regression slopes. Quantile-

181 specific expressivity was assessed by: 1) estimating the quantile-specific $\beta$-coefficients $( \pm \mathrm{SE})$ for

182 the 5 th, 6th,..., 95th percentiles of the sample distribution; 2) plotting the quantile-specific $\beta$

183 coefficient vs. the quantile of the trait distribution; and 3) testing whether the quantile-specific $\beta$ -

184 coefficients were constant, or changed as a linear, quadratic, or cubic functions of the percentile

185 of the trait distribution using orthogonal polynomials [38]. Falconer and Mackay's formula [26]

186 equates narrow-sense heritability $\left(h^{2}\right)$ to $h^{2}=2 \beta_{\mathrm{OP}} /\left(1+\mathrm{r}_{\text {spouse }}\right)$ and to $h^{2}=\left\{\left(1+8 \beta_{\mathrm{FS}} \mathrm{r}_{\text {spouse }}\right)^{0.5}\right.$ -

$1871\} / 2 r_{\text {spouse }}$ under specific restrictive assumptions, where $r_{\text {spouse }}$ is the spouse correlation.

188 "Quantile-dependent expressivity" is the biological phenomenon of the trait expression being

189 quantile-dependent, whereas "quantile-specific heritability" refers to the heritability statistic.

190

191 The finding of other studies were analyzed from the perspective of quantile-dependent

192 expressivity from the genotype-specific mean CRP concentrations cited in the original articles or

193 by calculating these values from the published graphs using the formatting palette for Microsoft

194 Powerpoint (Microsoft corporation, Redmond WA, version 12.3.6 for Macintosh computers) as

195 previously employed [27]. The weighted average of the geometric means or median values were

196 used to approximate average concentration by condition or pooled genotypes. The interpretations

197 of the current report are not necessarily the same those of the original articles.

198

199 Data availability: The data are not being published in accordance with the data use agreement

200 between the NIH National Heart Lung, and Blood Institute and Lawrence Berkeley National

201 Laboratory. However, the data used in the analyses are available from NIH National Heart

202 Lung, and Blood Institute Biologic Specimen and Data Repository Information Coordinating

203 Center through the website https://biolincc.nhlbi.nih.gov/my/submitted/request/ [39]. There are

204 some restrictions to the availability of these data. Researchers wishing a copy of the data should

205 contact the Blood Institute Biologic Specimen and Data Repository Information Coordinating 
206 Center at the website provided above, which provides information on human use approval and 207 data use agreement required. The $\mathrm{dbGaP}$ study home page [40] provides public summary-level 208 phenotype information.

209

210

211

Results

212

213 Eight of the 4078 offspring in the Third Generation Cohort lacked at least one CRP

214 measurement, and 317 lacked parental information. There was little difference between offspring included vs. excluded from the offspring-parent regression analysis for the proportion of female (mean \pm SE: $53.3 \pm 0.8$ vs. $54.0 \pm 2.8 \%$ ), age ( $40.1 \pm 0.1$ vs. $41.2 \pm 0.6$ years), BMI

217 (27.4 \pm 0.1 vs. $28.0 \pm 0.3)$, and CRP concentrations ( $2.59 \pm 0.06$ vs. $3.21 \pm 0.30 \mathrm{mg} / \mathrm{L})$. Six hundred ninety three participants of the Third Generation Cohort were excluded from the full-sib analysis because they lacked siblings. Again there was little difference between those included vs. excluded from the full-sib regression analysis for the proportion of female (mean \pm SE: 53.0 \pm 0.9 vs. $55.0 \pm 1.9 \%$ ), age ( $40.4 \pm 0.1$ vs. $38.8 \pm 0.4$ years), $\mathrm{BMI}(27.4 \pm 0.1$ vs. $27.4 \pm 0.2)$, and CRP concentrations $(2.58 \pm 0.07$ vs. $2.90 \pm 0.17 \mathrm{mg} / \mathrm{L})$.

223

224

Traditional estimates of familial concordance and heritability. Table 1, which displays the 225 sample characteristics, shows that average CRP were significantly higher in women than men. As expected CRP-concentrations were correlated positively with BMI $(\mathrm{r}=0.38)$ and were higher in smokers than nonsmokers (difference $\pm \mathrm{SE}: 0.54 \pm 0.18, \mathrm{P}=0.008$ ) when age and sex adjusted. The spouse correlation for adjusted CRP concentrations was negligible $\left(\mathrm{r}_{\text {spouse }}=-0.0013\right)$ for untransformed CRP and weak ( $\left.\mathrm{r}_{\text {spouse }}=0.0482\right)$ for $\log \mathrm{CRP}$. There were 1718 offspring with one parent and 1232 offspring with two parents. The offspring-parent regression slope for adjusted CRP concentrations ( $\left.\beta_{\mathrm{OP}} \pm \mathrm{SE}: 0.06 \pm 0.01\right)$ corresponds to a heritability $\left(h^{2}\right)$ of $0.11 \pm 0.02$. There were 5703 full-sibs in 2036 sibships with age and sex-adjusted CRP concentrations, whose full233 sib regression slope $\left(\beta_{\mathrm{FS}}\right)$ was $0.08 \pm 0.02$, which from Falconer's formula, corresponds to a 234 heritability of $h^{2}=0.15 \pm 0.03$. Heritability in female offspring was somewhat greater than in male 235 offspring whether computed from $\beta_{\mathrm{OP}}(0.13 \pm 0.03$ vs. $0.08 \pm 0.03)$ or $\beta_{\mathrm{FS}}(0.20 \pm 0.06$ vs. 
$2360.10 \pm 0.06)$, but not significantly so. Heritabilities for log CRP derived from $\beta_{\mathrm{OP}}(0.43 \pm 0.03)$ or

$237 \beta_{\mathrm{FS}}(0.37 \pm 0.03)$ were consistent with published reports [3].

238

239 Quantile-dependent expressivity. Figure 1A presents the offspring-parent regression slopes at the $24010^{\text {th }}, 25^{\text {th }}, 50^{\text {th }}, 75^{\text {th }}$, and $90^{\text {th }}$ percentiles of the offspring's CRP distribution along with their

241 corresponding heritability estimates. The slopes get progressively greater with increasing

242 percentiles of the CRP distribution. At the $90^{\text {th }}$ percentile, heritability was 0.33 or nearly 18 -fold 243 greater than the heritability at the $10^{\text {th }}$ percentile $\left(\mathrm{P}_{\text {difference }}=0.001\right)$. Figure $1 \mathrm{~B}$, which presents all

244 slopes between the $5^{\text {th }}$ and $95^{\text {th }}$ percentiles, shows a linear increase in heritability (i.e., slope \pm SE:

$\left.2450.0038 \pm 0.0010, \mathrm{P}_{\text {linear }}=0.0004\right)$ as the percentiles of the offspring's distribution increase. There

246 was no significant evidence of nonlinearity (i.e., $\mathrm{P}_{\text {quadratic }}=0.09 ; \mathrm{P}_{\text {cubic }}=0.31$ ). Quantile-specific

247 heritabilities were individually significant $(\mathrm{P} \leq 0.04)$ for all percentiles between the $17^{\text {th }}$ and $92^{\text {nd }}$

248 percentiles of the offspring's distribution. If the heritabilities over all quantiles were constant,

249 then the line segments would be parallel in Figure 1A, and the graph in Figure 1B would show a

250 flat line with zero slope. Figure $1 \mathrm{C}$ displays the full-sib quantile regression slopes $\left(\beta_{\mathrm{FS}}\right)$ and the

251 corresponding estimated $h^{2}$. Each percent increment in the CRP distribution was associated with

252 a $0.0027 \pm 0.0008$ increase in the full-sib regression slope $\left(P_{\text {linear }}=0.0008\right)$ and a $0.0054 \pm 0.0016$

253 increase in heritability.

254

255 Figure 2 presents quantile-specific heritability for logarithmically transformed CRP. The

256 transformation replaced the significant linear trend for a quadratic trend showing the greatest

257 heritability near the median and declining heritability moving away from the median when

258 estimated from offspring-parent pairs $\left(\mathrm{P}_{\text {quadratic }}=0.001\right)$ and full siblings $\left(\mathrm{P}_{\text {quadratic }}=0.06\right)$. 259

Discussion

261

262 Our analyses of the Framingham Heart Study provide consistent evidence for quantile-specific

263 heritability of untransformed serum CRP concentrations from both offspring-parent and full-sib

264 age- and sex-adjusted values. Heritability at the $90^{\text {th }}$ percentile of the CRP distribution

$265(0.33 \pm 0.10)$ was 18 -fold greater than at the $10^{\text {th }}$ percentile $(0.02 \pm 0.01)$ when estimated from

266 offspring-parent pairs, and 15-fold greater when estimated from full sibs. These are substantial 
267 differences that exceed those reported for high-density lipoprotein cholesterol $\left(48 \% h^{2}\right.$ increase 268 in going from the $10^{\text {th }}$ to $90^{\text {th }}$ percentile) [15], adiponectin (72\%) [19], total cholesterol (74\%)

269 [17], leptin (4.7-fold greater [18]), or triglycerides concentrations (13-fold) [14], or BMI (3.1270 fold) [13]. We analyzed heritability because it represents $30 \%$ to $50 \%$ of the CRP additive 271 genetic variance vis-à-vis the 5\% of the CRP variance attributable to 18 specific loci identified 272 by Dehghan et al. as genomewide significant [33].

273

274 There are, however, important limitations to our analysis of familial phenotypes: 1) Falconer's 275 formula probably do not adequately address the true complexity CRP genetics; and 2) heritability 276 lacks the specificity of directly measured genotypes. Re-evaluating other published studies that 277 measured genetic variants directly from the perspective of quantile-dependent expressivity may 278 partly address these concerns. Consistent with quantile-dependent expressivity, the examples 279 presented below show larger genetic effect sizes in association with the higher CRP 280 concentrations of low-level inflammation. Additional examples are presented that suggest the 281 phenomenon may apply to CRP acute phase reaction. Although several authors do point out that 282 genetic variant affecting acute phase CRP response are also evident for basal CRP concentrations $283[6,35,41]$, to the best of our knowledge, quantile-specific heritability has never been formally 284 acknowledged as a fundamental property of CRP genetics.

285

286 The CRP gene is located on chromosome 1q32 and includes two exons and one intron. CRP 287 genetic variants that are reported to affect CRP concentrations include rs2794521 ( $-717 \mathrm{~A}>\mathrm{G})$, 288 rs3091244 (-286C > T >A), rs $1800947(+1059 \mathrm{G}>\mathrm{C})$, rs $1130864(+1444 \mathrm{C}>\mathrm{T})$ and rs $1205(+2147$

$289 \mathrm{~A}>\mathrm{G})$. Rs2794521 and rs3091244 are located in the promoter region, rs1800947 in exon 2, 290 rs1130864 in the 3' untranslated region, and rs1205 occur in the 3' flanking region [42].

291 Rs3091244 has been shown to affect CRP transcriptional activity in vitro [43]. Rs1800947 is 292 silent [44]. Higher basal CRP concentrations are reported for the rs3091244 A-allele, rs1800947 293 GG-homozygotes, rs1130864 T-allele, and the rs1205 G-allele [35]. Interleukin-6 (IL-6), the 294 primary inflammatory cytokine stimulus for CRP [45], has two polymorphisms whose minor 295 alleles are reported to increase CRP concentrations: rs1800795 (-174G>C) [46] and rs1800796 $296(-572 \mathrm{G}>\mathrm{C})$ [47]. The tumor necrosis factor $\alpha(\mathrm{TNF}-\alpha)$ rs 1800629 (G-308A) polymorphism has 297 been shown to increased TNF- $\alpha$ production in vitro [48], and in turn, stimulate hepatic CRP 
298 production [49]. Carriers of the APOE $\varepsilon 4$ allele have lower CRP-concentrations than non299 carriers [50-53].

300

301 Adiposity. BMI, waist circumference and fat body mass are associated with significantly higher 302 CRP concentrations, accounting for five to seven percent of log CRP variation [54]. Visceral 303 adipose tissue in particular promotes higher IL-6 concentrations [55] and low-grade CRP 304 inflammation [56,57]. CRP concentrations decrease an average of $0.13 \mathrm{mg} / \mathrm{L}$ per $\mathrm{kg}$ of weight 305 loss [58].

306

307 Consistent with quantile-dependent expressivity and the higher CRP concentrations of obese 308 subjects, Friedlander et al. [59] reported that the heritability of untransformed CRP was nearly 309 three-fold greater in obese than nonobese subjects ( 0.670 vs. 0.256$)$. In addition, data reported by 310 Farup et al. [60] showed that the CRP difference between non-carriers and carriers of the $A P O E$ $311 \varepsilon 4$-allele decreased linearly as average CRP concentrations decreased in morbidly obese patients 312 undergoing weight loss (Figure 3A). Specifically, the genotype difference was greatest at 313 baseline ( $\varepsilon 4-$ vs. $\varepsilon 4+: 8.2$ vs. $5.3 \mathrm{mg} / \mathrm{L}, \mathrm{p}=0.004$ ) when average CRP was highest, intermediate 314 six months later (5.2 vs. $3.1 \mathrm{mg} / \mathrm{L}, \mathrm{p}=0.007)$ for the lower average CRP from losing $3.0 \mathrm{~kg} / \mathrm{m}^{2}$ on 315 a conservative weight loss program, and smallest ( 1.3 vs. $0.7 \mathrm{mg} / \mathrm{L}, \mathrm{p}=0.03)$ when average CRP 316 was least after losing an additional $10.7 \mathrm{~kg} / \mathrm{m}^{2}$ during the year following bariatric surgery.

318 Cross-sectional data support these results. Pramudji et al. [61] reported that CRP concentrations 319 increased with the number of C-alleles of the IL-6 rs 1800795 polymorphism for obese $(\mathrm{P}=0.02)$ 320 but not non-obese Indonesians $(\mathrm{P}=0.64)$, consistent with the higher average CRP concentrations 321 of those who were obese (2.26 vs. $0.49 \mathrm{mg} / \mathrm{L}$, Figure 4A). Teng et al. [62] reported that the 322 effects of obesity on Taiwanese CRP concentrations differed significantly by rs 2794521

$323\left(\mathrm{P}_{\text {interaction }}=0.03\right.$, Figure 4B histogram $)$ and $\mathrm{rs} 1800947\left(\mathrm{P}_{\text {interaction }}=0.02\right.$, Figure $4 \mathrm{C}$ histogram $)$, and 324 possibly rs1205 (Figure 4D histogram). Correspondingly, average CRP levels were 325 approximately twice as high in the obese than non-obese subjects, and as shown in the associated 326 line graphs, the interactions could be attributed to a larger genetic effect size at higher average 327 CRP concentrations. Studies by Eiriksdottir et al. [54], Todenti et al. [63], and Wang et al. [64] 328 all present results consistent with a larger rs 1205 genotype differences at the higher average CRP 
329 concentrations of those who are more overweight. Eiriksdottir et al. reported that the $\log$ CRP 330 difference between rs1205 G-carriers and AA homozygotes increased as CRP levels increased

331 with increasing BMI in both men $\left(\mathrm{P}_{\text {interaction }}=0.05\right)$ and women $\left(\mathrm{P}_{\text {interaction }}=0.09\right)$ [54].

332

333 Smoking. The Speedwell Survey of British men reported that average CRP increased

334 significantly from those who never smoked $(1.13 \mathrm{mg} / \mathrm{L})$, to those who averaged 1-14 (1.87

$335 \mathrm{mg} / \mathrm{L}), 15-24(2.32 \mathrm{mg} / \mathrm{L})$, and greater than 25 cigarettes/day (2.05 mg/L) [65]. Consistent with

336 quantile-dependent expressivity, Friedlander et al. [59] reported that the heritability of

337 untransformed CRP was 4-fold larger in smokers than nonsmokers (0.863 vs. 0.193), and

338 Retterstol et al. [66] reported a higher $\mathrm{MZ}$ twin correlation in smokers than nonsmokers $(\mathrm{r}=0.49$

339 vs. $r=0.34$ ).

340

341

Luetragoon et al. [67] reported a significant CRP difference between smokers and nonsmokers in

342 the $C R P$ rs1800947 CC homozygotes $(\mathrm{P}=0.03)$ but not $\mathrm{G}$-allele carriers $(\mathrm{P}=0.67$, Figure $4 \mathrm{E}$

343 histogram), corresponding to a larger genotype difference for the higher CRP concentrations of

344 the smokers vs. nonsmokers (2.57 vs. $1.34 \mathrm{mg} / \mathrm{L}, \mathrm{P}=0.009$ line graph). Shin et al. [68] reported a

345 significant interaction between smoking and the IL-6 rs 1800796 promoter polymorphism in their

346 effect on CRP concentrations $\left(\mathrm{P}_{\text {interaction }}=0.04\right)$. Whereas the Figure 4F histogram shows that the

347 effect of smoking on CRP was greater in GG homozygotes, the line graph suggests that the

348 results could also be interpreted in part as a larger genetic effect size at the higher CRP

349 concentrations of the smokers. Data presented by Gander et al. in their figure 1 [69] suggest a

350 greater smoking effect in carriers of the A-allele than GG homozygotes of the TNF- $\alpha$ rs 1800629

351 polymorphism (Figure 5A), corresponding to a larger difference between genotypes at the higher

352 average estimated concentrations of the smokers.

353

354 Physical activity. Brull et al. [70] reported overall mean CRP concentrations in British army 355 recruits increased significantly following an intensive 48-hour final military endurance exercise 356 (1.14 mg/L post-exercise vs. $0.59 \mathrm{mg} / \mathrm{L}$ at baseline). Figure $5 \mathrm{~B}$ shows that the exercise-induced 357 CRP increases were over 2.5-fold greater in rs1130864 TT homozygotes than C-allele carriers 358 (histogram), and that the difference between genotypes was two-fold greater 2 hours post 
359 exercise than at baseline (1.28 vs. $0.49 \mathrm{mg} / \mathrm{L}$ difference) corresponding to the higher post-

360 exercise mean concentrations (line graph).

361

362 Diet. A Mediterranean-style diet that is rich in monounsaturated fat, polyunsaturated fat, and

363 fiber was reported to significantly decrease CRP concentrations relative to a prudent diet [71]. In

364 T2DM, Keramet et al. [72] reported a greater effect of monounsaturated fat intake on CRP

365 concentrations in CC homozygotes of the APOA2 rs5082 polymorphism than in carriers of the

366 T-allele (Figure 5C histogram, $\mathrm{P}_{\text {interaction }}=0.02$ ). The line graph suggests there were greater

367 genotype differences and average CRP concentrations below vs. above median intake of

368 monounsaturated fatty acids.

369

370 Our analysis of Carvalho-Wells et al. data suggest that $A P O E \varepsilon 3 \varepsilon 3$ subjects who switched from

371 an 8-wk low fat to an 8-wk high fat diet had somewhat greater increases in CRP than $\varepsilon 3 \varepsilon 4$

372 subjects [73]. Figure 5D shows a larger difference between genotypes at the significantly higher

373 CRP concentrations of the high-fat vis-à-vis the low-fat diet. Supplementing the high-fat diet

374 with $3.45 \mathrm{~g}$ of DHA-rich oil eliminated the genotype difference (not displayed).

375

376 Gomez-Delgado et al. [74] reported that decreases in CRP concentrations from switching from

377 the basal to a low-fat diet were greater in CC-homozygotes of the circadian locomotor output

378 cycles kaput $(C L O C K)$ rs4580704 polymorphism than in carriers of the G-allele $(\mathrm{P}<0.001)$.

379 Cross-sectionally, the histogram of Figure 5E shows that the CRP difference between consuming

380 a low fat diet vs. a Mediterranean diet for one year was greater for carriers of the G-allele than

381 CC homozygotes (histogram), while the line graph shows that the difference between rs4580704

382 genotypes was greater for the higher CRP concentrations of the low-fat diet than for the lower

383 CRP concentrations of the Mediterranean diet.

384

385

Elevated Coronary Heart Disease (CHD) risk. Zee and Ridker [75] reported that baseline

386

median CRP concentrations in healthy men who experienced their first arterial thrombosis

387 (nonfatal MI, nonfatal stroke, or cardiovascular death) during 8.6-year follow-up were

388 significantly higher than matched controls who remained event free (1.43 vs. $1.23 \mathrm{mg} / \mathrm{L}$,

$389 \mathrm{P}=0.006)$. The CRP difference between those experiencing and not experiencing thrombosis was

Peer) reviewing PDF | (2020:10:53970:1:1:CHECK 8 Jan 2021) 
390 greater in rs1800947 GG homozygotes than GC heterozygotes (Figure 5F histogram), which

391 corresponded to a larger genotype difference at the higher median baseline CRP concentrations

392 of those with a thrombotic destiny (Figure 5F line graph) [75].

393

394 Myocardial infarction survivors. Data reported by Kovacs et al. [76] showed that the CRP

395 difference between carriers and non-carriers of the rs3091244 A-allele was greater in myocardial

396 infarction survivors $(\mathrm{P}<0.02)$ than matched controls (NS), consistent with the higher estimated

397 median concentrations of the survivors (1.46 vs. $0.96 \mathrm{mg} / \mathrm{L}$, Figure $6 \mathrm{~A})$.

398

399 Stroke. Ben-Assayag et al. [77] reported that CRP differences between G-allele carriers and AA

400 homozygotes of the rs2794521 polymorphism were significant at admission following a stroke or

401 transient ischemic attack (2.02 vs. $1.73 \mathrm{mg} / \mathrm{L}, \mathrm{P}=0.03)$ when average CRP concentrations were

402 elevated (1.71 g/L) but not six-months later (1.44 vs. $1.43 \mathrm{mg} / \mathrm{L}, \mathrm{P}=0.98)$ when average CRP

403 concentrations were lower $(1.43 \mathrm{mg} / \mathrm{L})$. The CRP change between admission and six-month

404 follow-up was significantly greater in the G-allele carriers than AA homozygotes $(\mathrm{P}=0.05)$.

405

406 Type 2 diabetes mellitus Subclinical systemic inflammation contributes to the etiology of insulin

407 resistance [78], which may explain the increased diabetes risk associated with elevated CRP

408 concentrations prospectively [79]. The missense variant rs8192284 of the interleukin-6 receptor

409 (IL6R) gene is reported to be strongly associated with IL-6 and CRP concentrations in

410 genomewide association studies [80]. Qi et al. reported a significant interaction $\left(\mathrm{P}_{\text {interaction }}=0.03\right)$

411 between diabetes and rs8192284 in their affect on CRP concentrations (Figure 6B histogram)

412 [80]. However, diabetic had higher estimated CRP concentrations than non-diabetics, and the

413 interaction could be due to the larger genetic effect size at the higher average CRP

414 concentrations of the T2DM (Figure 6B line graph).

415

416 Peripheral arterial disease (PAD). The IL-6 rs 1800795 polymorphism has been suggested to

417 affect IL-6 expression and influence the development of PAD, a vascular pathology associated

418 with T2DM [81]. Data reported by Libra et al. [81] showed that the CRP difference between

419 T2DM patients with and without PAD was greater in GG homozygotes than C-allele carriers

420 (2.0 \pm 0.34 vs. $-0.16 \pm 0.26 \mathrm{mg} / \mathrm{L}$, Figure 6C histogram). Average CRP concentrations were higher

Peer) reviewing PDF | (2020:10:53970:1:1:CHECK 8 Jan 2021) 
421 in the PAD+ than PAD- patients $(3.22 \pm 0.16$ vs. $2.06 \pm 0.13 \mathrm{mg} / \mathrm{L})$, and correspondingly, the

422 difference between genotypes was greater for PAD+ than PAD- (3.25 $\pm 0.32 \mathrm{vs} .1 .09 \pm 0.28 \mathrm{mg} / \mathrm{L})$.

423

424 Sex. Females have higher CRP concentrations than men, which may be hormonal, i.e., female

425 CRP concentrations correlate positively with estradiol levels, and the odds of CRP falling above

426 the median doubles with each standard deviation increment in endogenous estradiol [82]. Higher

427 female CRP may explain the greater estimated heritability we observed in female than male 428 offspring ( 0.13 vs. 0.08$)$ and female than male sibling ( 0.20 vs. 0.10$)$, the greater heritability of 429 untransformed CRP in females than males reported by Friedlander et al. (0.352 vs. 0.150) [59], 430 and the higher within-pair correlations in female than male MZ twins reported by Retterstol et al. $431 \quad(\mathrm{r}=0.44$ vs. $\mathrm{r}=0.31)[66]$.

432

433 Race. CRP concentrations tend to be higher in Blacks than other racial groups [83], i.e., mean 434 CRP concentrations estimated from meta-analysis are $2.6 \mathrm{mg} / \mathrm{L}$ for African-Americans, 2.51 for 435 Hispanics, 2.03 for White Americans, and 1.01 for East Indians [84]. European ancestry is 436 negatively correlated with age-adjusted CRP in both African-Americans $(\mathrm{p}<0.0001)$ and 437 Hispanic Americans ( $\mathrm{p}=0.001$ ) [85]. Quantile-dependent expressivity may contribute to the 438 higher heritability of lnCRP in Blacks than whites (53\% vs. 31\%) reported by Wu et al. [86] 439

440 Acute phase response. Rapid hepatic synthesis of CRP occurs as part of the acute phase 441 response to infection, injury or trauma [4,34]. The increase can be 1000-fold [4,34]. Consistent 442 with quantile-dependent expressivity, several SNPs show effects on CRP that are greatly 443 accentuated during acute phase response vis-à-vis their basal concentrations, and intermediate 444 effects during intermediate transitional concentrations.

445

446 Coronary artery bypass grafting $(\mathrm{CABG})$ surgery produces a strong inflammatory response with 447 substantially increased CRP, fibrinogen, and IL-6 circulating concentrations [70,87]. Wypasek et 448 al. [87] reported that CRP increased from a pre-operative concentration of $4.3 \pm 0.1 \mathrm{mg} / \mathrm{L}$ to $44962.5 \pm 4.2 \mathrm{mg} / \mathrm{L}$ five to seven days following CABG surgery $(\mathrm{P}<0.0001)$. Consistent with 450 quantile-dependent expressivity, the line graph of Figure 6D shows that the increase in mean 451 concentrations coincided with substantially greater post-operative CRP differences between 
452 carriers and non-carriers of the $\mathrm{T}$ allele of the fibrinogen beta-chain $(F G B)-148 \mathrm{C}>\mathrm{T}$ rs 1800787

453 polymorphism $(70.4 \pm 5.0$ vs. $51.6 \pm 4.25 \mathrm{mg} / \mathrm{L}, \mathrm{p}=0.005)$ vis-à-vis their much smaller pre-

454 operative difference ( $7.49 \pm 1.2$ vs. $4.26 \pm 1.0 \mathrm{mg} / \mathrm{L}, \mathrm{p}=0.04)$. Another report by Wypasek et al.

455 [88] showed that post-operative CRP concentrations were significantly higher in C-allele carriers 456 than non-carriers of the IL-6 rs 1800795 polymorphism $(56.39 \pm 4.27$ versus $36.60 \pm 7.78 \mathrm{mg} / \mathrm{L}, \mathrm{P}$ $457=0.03)$ when average CRP concentrations were elevated $(54.9 \pm 3.8 \mathrm{mg} / \mathrm{L})$, which was 458 substantially greater than the pre-operative difference between genotypes $(4.1 \pm 0.35$ vs. $2.4 \pm$ $4590.59 \mathrm{mg} / \mathrm{L}, \mathrm{P}=0.02)$ when average $\mathrm{CRP}$ concentrations were much lower $(3.71 \pm 0.45$, Figure $6 \mathrm{E})$. 460

461 Mathew et al. [89] reported a substantial increase in mean CRP concentrations following CABG 462 and cardiopulmonary bypass that was significantly affected by the rs 1800947 polymorphism 463 (Figure 6F, $\mathrm{P}=0.01$ ). Twenty-four hour post cross-clamp CRP levels were significantly higher in 464 GG homozygotes than $\mathrm{CC}$ homozygotes and $\mathrm{CG}$ heterozygotes $(\mathrm{P}<0.001)$. The greater post465 operative CRP increase in GG than C-allele carriers (histogram) corresponds to a small pre466 operative genotype difference when the average CRP concentration was $3.4 \mathrm{mg} / \mathrm{L}$ vs. a large 467 postoperative genotype difference when average CRP concentration was $45.6 \mathrm{mg} / \mathrm{L}$.

468

469 Perry et al. [90] reported that median peak CRP went from $1.2 \mathrm{mg} / \mathrm{L}$ preoperatively to 293.3 $470 \mathrm{mg} / \mathrm{L}$ postoperatively following CABG surgery. The rs3091244 T-allele was associated with 471 higher peak postoperative CRP $\left(\mathrm{P}=2.1 \times 10^{-3}\right)$, whilst the rs1800947 C-allele of was associated 472 with lower peak postoperative levels $\left(\mathrm{P}=2.4 \times 10^{-4}\right)$. Compared to their most common haplotype 473 (rs1800947G/rs3091244C), the peak postoperative levels were significantly lower for haplotype $4744(\mathrm{CC}, \mathrm{P}=0.004)$ and significantly higher for haplotype $2(\mathrm{GT}, \mathrm{P}=0.03)$. Figures $3 \mathrm{~B}$ and $3 \mathrm{C}$ show 475 that the postoperative genotype differences increased with increasing CRP concentrations, 476 consistent with quantile-dependent expressivity.

477

478 Brull et al. [70] reported an 83-fold increase in average CRP, from a preoperative $1.97 \pm 0.36$ $479 \mathrm{mg} / \mathrm{L}$ to a post-operative $167.2 \pm 5.0 \mathrm{mg} / \mathrm{L}$, seventy-two hours after $\mathrm{CABG}$ surgery $(\mathrm{P}<0.0005)$, 480 and that CRP concentrations remained significantly elevated through post-operative day five 481 ( $\mathrm{P}<0.0005)$. The rs1130864 TT-homozygotes had significantly higher CRP levels than C-allele 482 carriers at all time points $>24$ hours post-operation, but not before. Our analysis of their figure 
483 2A suggests that rs1130864 genotype differences were significantly related to average CRP 484 concentrations during the acute phase response (Figure $3 \mathrm{D}, \mathrm{P}=0.02$ ).

485

486

Intensive periodontal therapy also causes sharp rises in CRP and IL- 6 that peak by $24 \mathrm{~h}$ and

487

488

489

490

491

492

493

494

495

496

497

498

499

500

501

502

503

504

505

506

507

508

509

511

510 Consistent with quantile-dependent expressivity, the line graphs show greater genotype 512 elevated vis-a-vis the chronic stable phase. Results reported by Kovacs et al. [76] for rs3091244 513 are consistent with Suk Danil's results (Figure 7D). remain elevated for up to 7 days [91]. D'Aiuto et al. [41] reported significantly higher CRP concentrations in rs1130864 TT homozygotes than C-allele carriers one $(21.10 \mathrm{vs} .12 .37 \mathrm{mg} / \mathrm{L}$, $\mathrm{P}=0.02)$ and seven-days (4.89 vs. $3.08 \mathrm{mg} / \mathrm{L}, \mathrm{P}<0.01)$ during the inflammatory stimulus of periodontal intensive therapy. Correspondingly, the geometric means of CRP concentrations were elevated one $(13.64 \mathrm{mg} / \mathrm{L}, \mathrm{P}<0.0001)$ and seven days $(3.35 \mathrm{mg} / \mathrm{L}, \mathrm{P}<0.0001)$ relative to baseline $(1.93 \mathrm{mg} / \mathrm{L})$, such that the intermediate 7-day genotype difference was as predicted by linear interpolation using the 7-day average CRP concentration relative to baseline and day one average concentrations (Figure 3E). Similarly, Motoyama et al.'s [92] data showed that the CRP difference between rs1800947 GG homozygotes than C-allele carriers after curative esophagectomy was linearly related to average CRP concentrations, and that the intermediate 12 hours genotype difference was almost exactly predicted by it's intermediate average concentration by linear interpolation (Figure 3F).

CRP concentrations also increase substantially during acute ischemia and return to near basal levels during the chronic stable phase after ischemia is resolved [42]. Recurrent myocardial infarction and cardiovascular death are strongly related to CRP increases during acute coronary syndrome [42]. Suk Danil et al. [42] reported that rs3091244 AA homozygotes had the highest $(76.6 \mathrm{mg} / \mathrm{L})$ median concentrations during the acute rise in plasma CRP-concentrations following an acute coronary syndrome whereas the median concentration in noncarriers was 11.1 $\mathrm{mg} / \mathrm{L}$. Figures 7A-7C show that during both acute coronary syndrome and the chronic stable phase one month later, CRP concentrations were significantly higher in rs3091244 A-allele carriers than non-carriers $(\mathrm{P}=0.0005$ and $\mathrm{P}=0.0008$, respectively), rs 1800947 GG-homozygotes than $\mathrm{C}$-allele carriers (both $\mathrm{P}<0.0001$ ), and per dose of the rs1205 G-allele (both $\mathrm{P}<0.0001$ ).

11 differences during acute coronary syndrome when median CRP concentrations were substantially 
514

515 Infection. Mölkänen et al. [93] reported greater differences in CRP concentrations between

516 carriers and non-carriers of the rs3091244 A-allele at peak CRP concentrations (103 mg/L

517 difference, $\mathrm{P}=0.004$ ) during the first week of a Staphylococcus aureus bacteremia when average

$518 \mathrm{CRP}$ was approximately $190 \mathrm{mg} / \mathrm{L}$, than 7-days after diagnosis ( $5 \mathrm{mg} / \mathrm{L}$ difference, $\mathrm{P}=0.77$ )

519 when average CRP concentrations had decreased to approximately $43 \mathrm{mg} / \mathrm{L}$ (Figure 7E).

520

521 Chronic rheumatoid arthritis. Ammitzboll et al. [7] reported that rs1205 TT homozygotes had

$52250 \%$ lower CRP concentrations than $\mathrm{CC}$ homozygotes at baseline $(\mathrm{P}=0.005)$ when average

523 concentrations were approximately $16.6 \mathrm{mg} / \mathrm{L}$ in patients with untreated early chronic

524 rheumatoid arthritis, but not after 1 -year $(\mathrm{P}=0.38)$ when antirheumatic drug and steroid treatment

525 had decreased average CRP concentrations to approximately $4.1 \mathrm{mg} / \mathrm{L}$ (Figure 7F). Another

526 study of rheumatoid arthritis patients by Rhodes et al. [6] compared CRP concentrations across

527 genotypes using erythrocyte sedimentation rate (ESR) as an independent measure of

528 inflammation. Their data showed larger estimated CRP differences between genotypes at an ESR

529 of 80 vs. 40 for rs1800947 (CC/GC/GG: 19.4/28.6/42.2 vs. 12.0/17.7/26.1 mg/L), rs1205

530 (AA/GA/GG: 27.6/35.5/45.7 vs. 17.0/21.9/28.2 mg/L), and rs11265257 (AA/GA/GG:

$53129.2 / 37.3 / 47.6$ vs. 17.9/22.9/29.2 mg/L), which quantile-dependent expressivity would attribute

532 to the higher average CRP when ESR was 80 than 40 (approximately 40 vs. $24 \mathrm{mg} / \mathrm{L}$ ). Wielińska

533 et al. [8] reported larger differences between genotypes for genes coding for the receptor

534 activator of nuclear factor $\kappa \mathrm{B}$ (RANK rs8086340) and its ligand (RANKL rs7325635) in

535 rheumatoid arthritis patients prior to 12 weeks of anti-TNF treatment when average CRP

536 concentrations were high $(23.6 \mathrm{mg} / \mathrm{L})$, than after treatment when average concentrations were

537 lower $(9.84 \mathrm{mg} / \mathrm{L}$, Figure 8A, 8B).

538

539 Inflammatory bowel disease (IBD). TNF- $\alpha$ is both a major regulator of hepatic CRP production

540 and a key inflammatory mediator in IBD pathophysiology [94]. Data presented by Vatay et al.

541 [10] show median CRP concentrations were substantially higher in GA heterozygotes than GG

542 homozygotes of the TNF- $\alpha$ rs 1800629 polymorphism for the high CRP concentrations of active

543 phase IBD, but not for the low CRP concentrations of matched healthy controls (Figure 8C). 
545 Ankylosing spondylitis. This is a spinal inflammation whose severity, clinical progression, and

546 treatment response are indicated by elevated CRP concentrations. Etanercept, a TNF- $\alpha$ inhibitor,

547 is one of the few treatment options for ankylosing spondylitis. Xu et al. [9] reported that

548 rs3091244 AA homozygotes have higher CRP concentrations than carriers of the G allele both

549 before and after 12-week etanercept treatment, but that this difference in genotypes was over

550 two-fold greater prior to treatment when average CRP was high vis-à-vis post-treatment

551 concentrations (Figure 8D).

552

553 Dilated cardiomyopathy. Proinflammatory cytokines may contribute to dilated cardiomyopathy,

554 a condition distinguished by dilatation and impaired contraction of the left or both ventricles.

555 Liaquat et al. [95] reported that differences in CRP concentrations between idiopathic dilated

556 cardiomyopathy patients and healthy controls increased with the number of A-alleles of the

557 TNF- $\alpha$ rs1800629 polymorphism (Figure 8E histogram), and were greater in C-allele carriers of

558 the IL-6 rs1800795 polymorphism (Figure 8F histogram). Consistent with quantile-dependent

559 expressivity, the line graphs show that the effects of the genotypes were greater for the higher

560 mean concentrations of the patients than controls.

561

562 Kawasaki disease. Kawasaki disease is an inflammation of the walls of medium-size artery that

563 occurs affecting children. Kim et al. [96] reported that the CRP promoter rs 12068753 showed

564 greater CRP differences between genotypes in patients with Kawasaki disease than controls in

565 accordance with the cases' higher average CRP concentrations (8.9 vs. $0.3 \mathrm{mg} / \mathrm{dL}$, Figure 9).

566

567 Exceptions. Contrary to expectations: 1) Wu et al. [97] reported that the significant interaction

568 between activating transcription factor (AFT3) rs10475 and obesity on CRP concentrations

$569\left(\mathrm{P}_{\text {interaction }}=0.006\right)$ was due to a significant difference between genotypes $(\mathrm{P}=0.001)$ in non-obese

570 subjects having lower overall CRP concentrations and not obese subjects $(\mathrm{P}=0.27)$ whose CRP

571 concentrations were higher; 2) Keramat et al. [72] reported significantly greater APOA2 rs5082

572 genotype differences for the lower average CRP concentrations of low saturated fat intake than

573 for the higher average CRP concentrations above median saturated fat intake: 3) Hsu et al.'s [98]

574 report of significantly greater genotype differences for hepatic nuclear factor-1 $\alpha$ (HNF1A)

575 rs 1920792, rs2464196, and rs1169310 polymorphisms in nonobese than obese subjects despite

Peer) reviewing PDF | (2020:10:53970:1:1:CHECK 8 Jan 2021) 
576 the higher average CRP the obese; 4) Eklund et al's [99] report that CRP differed between IL6

577 rs 1800795 genotypes after weight loss when average CRP concentrations were decreased but not

578 before when average concentrations were higher; F) Retterstol et al.'s [66] report of a larger MZ

579 correlation below the median BMI than above ( $\mathrm{r}_{\mathrm{MZ}}=0.42$ vs. 0.31$)$ despite the positive correlation

580 between BMI and CRP. These exceptions to quantile-dependent expressivity may make them

581 noteworthy in themselves, however, most reported gene-environment interactions are

582 unreplicated, and it is expected that at least some of the reported interactions could be spurious.

583

584 Conclusion: Heritability of serum CRP concentration is quantile-specific, which may explain or

585 contribute to the inflated CRP differences between CRP (rs1130864, rs1205, rs1800947,

586 rs2794521 rs3091244), FGB (rs1800787), IL-6 (rs1800795, rs1800796), IL6R (rs8192284), TNF-

$587 \alpha(\mathrm{rs} 1800629)$ and $A P O E$ genotypes following CABG surgery, stroke, TIA, curative

588 esophagectomy, intensive periodontal therapy, or acute exercise; during acute coronary

589 syndrome or Staphylococcus aureus bacteremia; or in patients with chronic rheumatoid arthritis,

590 diabetes, peripheral arterial disease, ankylosing spondylitis, obesity or inflammatory bowel

591 disease or who smoke.

592

593 Quantile-dependent expressivity is a novel concept, and unsurprisingly, the majority of articles

594 do not provide the data in a form necessary to evaluate its applicability, namely genotype-

595 specific CRP concentrations stratified by characteristics affecting average CRP concentrations.

596 Although it is reported that CRP concentrations are higher in patients with abdominal aortic

597 aneurysm [100], poor cognitive performance and cognitive decline over time [101], anxiety

598 disorders [52], and Alzheimer's disease [102], it is not known whether these conditions affect the

599 effect size of CRP-related genetic variants.

600

601 Finally, we note that quantile regression and its bootstrap-derived standard errors do not require

602 a normal distribution, and provide insights into CRP inheritance heretofore unstudied. The

603 decision to logarithmically transform CRP concentration has been exclusively based on the

604 theoretical requirement of the parametric statistical testing rather than a biological rationale. All

605 the major genomewide association studies were performed on log CRP, as were virtually all tests

606 of association or gene-environment interaction. This statistical accommodation may work against 
607 the goal of identifying some SNPs affecting CRP concentrations given our results suggesting the 608 largest genetic effects are at the highest concentrations.

609

610

611

612 
614

References

615

616 1. Windgassen EB, Funtowicz L, Lunsford TN, Harris LA, Mulvagh SL. C-reactive protein 617 and high-sensitivity C-reactive protein: an update for clinicians. Postgrad Med.

618 2011;123:114-9. doi: 10.3810/pgm.2011.01.2252. PMID: 21293091.

619

620 2. Emerging Risk Factors Collaboration, Kaptoge S, Di Angelantonio E, Lowe G, Pepys

621

622

623 MB, Thompson SG, Collins R, Danesh J. C-reactive protein concentration and risk of

624

625

626 coronary heart disease, stroke, and mortality: an individual participant metaanalysis. Lancet. 2010;375(9709):132-40. doi: 10.1016/S0140-6736(09)61717-7.

627

628

3. Sas AA, Vaez A, Jamshidi Y, Nolte IM, Kamali Z, D Spector T, Riese H, Snieder H. Genetic and environmental influences on stability and change in baseline levels of Creactive protein: A longitudinal twin study. Atherosclerosis. 2017;265:172-178. doi:

629

630

631

4. Pepys MB, Hirschfield GM: C-reactive protein: a critical update. J Clin Invest 2003,

632

633 5. Hage FG, Szalai AJ. C-reactive protein gene polymorphisms, C-reactive protein blood levels, and cardiovascular disease risk. J Am Coll Cardiol. 2007 ;50:1115-22. doi: 10.1016/j.jacc.2007.06.012.

636

637

6. Rhodes B, Merriman ME, Harrison A, Nissen MJ, Smith M, Stamp L, Steer S, Merriman

638

639

640 TR, Vyse TJ. A genetic association study of serum acute-phase C-reactive protein levels in rheumatoid arthritis: implications for clinical interpretation. PLoS Med.

641

642 7. Ammitzbøll CG, Steffensen R, Bøgsted M, Hørslev-Petersen K, Hetland ML, Junker P, 643 2010;7:e1000341. doi: 10.1371/journal.pmed.1000341.

644 Johansen JS, Pødenphant J, Østergaard M, Ellingsen T, Stengaard-Pedersen K. CRP genotype and haplotype associations with serum C-reactive protein level and DAS28 in 
645

646

647

648

649

650

651

652

653

654

655

656

657

658

659

660

661

662

663

664

665

666

667

668

669

670

671

672

673

674

untreated early rheumatoid arthritis patients. Arthritis Res Ther. 2014;31;16:475. doi: 10.1186/s13075-014-0475-3.

8. Wielińska J, Kolossa K, Świerkot J, Dratwa M, Iwaszko M, Bugaj B, Wysoczańska B, Chaszczewska-Markowska M, Jeka S, Bogunia-Kubik K. Polymorphisms within the RANK and RANKL Encoding Genes in Patients with Rheumatoid Arthritis: Association with Disease Progression and Effectiveness of the Biological Treatment. Arch Immunol Ther Exp (Warsz). 2020;68(4):24. doi: 10.1007/s00005-020-00590-6.

9. $\mathrm{Xu} \mathrm{Y}$, Jiang $\mathrm{W}$, Zhang $\mathrm{H}$. Association between C-reactive protein gene variant and treatment efficacy of etanercept in ankylosing spondylitis patients receiving hip arthroplasty. J Clin Lab Anal. 2020;34(8):e23343. doi: 10.1002/jcla.23343.

10. Vatay A, Bene L, Kovács A, Prohászka Z, Szalai C, Romics L, Fekete B, Karádi I, Füst G. Relationship between the tumor necrosis factor alpha polymorphism and the serum Creactive protein levels in inflammatory bowel disease. Immunogenetics. 2003;55:247-52. doi: $10.1007 / \mathrm{s} 00251-003-0575-8$.

11. Ni P, Yu M, Zhang R, Cheng C, He M, Wang H, Chen S, Duan G. Dose-response association between C-reactive protein and risk of all-cause and cause-specific mortality: a systematic review and meta-analysis of cohort studies. Ann Epidemiol. 2020 Nov;51:2027.e11. doi: 10.1016/j.annepidem.2020.07.005.

12. Williams PT. Quantile-specific penetrance of genes affecting lipoproteins, adiposity and height. PLoS One. 2012;7:e28764. doi:10.1371/journal.pone.0028764

13. Williams PT. Quantile-dependent heritability of computed tomography, dual-energy $\mathrm{x}$-ray absorptiometry, anthropometric, and bioelectrical measures of adiposity. Int J Obesity 2020; 44:2101-2112. doi: 10.1038/s41366-020-0636-1. 
675 14. Williams PT. Gene-environment interactions due to quantile-specific heritability of 676 triglyceride and VLDL concentrations. Scientific Reports 2020;10:4486.

677 doi:10.1038/s41598-020-60965-9

678

679 15. Williams PT. Quantile-specific heritability of high-density lipoproteins with 680 681 implications for precision medicine. J Clin Lipid 2020;14:448-458.e0. doi:

682

683

16. Williams PT. Quantile-dependent expressivity and gene-lifestyle interactions 684 involving high-density lipoprotein cholesterol. Lifestyle Genomics 2020 (in press)

685

686

687

688 10.1016/j.jacl.2020.05.099

689

690

691

692

17. Williams PT. Quantile-specific heritability of total cholesterol and its

\section{7} pharmacogenetic and nutrigenetic implications. Int J Cardiol. 2020:S01675273(20)34241-8. doi: 10.1016/j.ijcard.2020.11.070.

18. Williams PT. Quantile-specific heritability of sibling leptin concentrations and its implications for gene-environment interactions. Sci Rep. 2020;10:22152. doi:

693

694

19. Williams PT. Quantile-dependent expressivity of plasma adiponectin concentrations 695 696 697 10.1038/s41598-020-79116-1.

\section{8}

699

700

701 may explain its sex-specific heritability, gene-environment interactions, and genotype-specific response to postprandial lipemia. PeerJ 2020;8:e10099. doi: 10.7717/peerj.10099

20. Williams PT. Spirometric traits show quantile-dependent heritability, which may contribute to their gene-environment interactions with smoking and pollution. PeerJ.

702

703 21. Williams PT. Quantile-specific heritability of intakes of alcohol but not other 704 705 macronutrients. Behav Genet. 2020; 2020;50:332-345. doi: 10.1007/s10519-02010005-z. 
706

707 22. Williams PT. Quantile-specific heritability may account for gene-environment

708 interactions involving coffee consumption. Behav Genet. 2020 50:119-26.

709

710 23. Rokholm B, Silventoinen K, Ängquist L, Skytthe A, Kyvik KO, Sørensen TI. Increased 711 genetic variance of BMI with a higher prevalence of obesity. PLoS One.

$712 \quad$ 2011;6:e20816.

713

714 24. Abadi A, Alyass A, Robiou du Pont S, Bolker B, Singh P, Mohan V, Diaz R, Engert JC, 715 Yusuf S, Gerstein HC, Anand SS, Meyre D. Penetrance of polygenic obesity

716

717 susceptibility loci across the body mass index distribution. Am J Hum Genet.

718

719

720 2012;101:925-938.

721

25. Beyerlein A, von Kries R, Ness AR, Ong KK. Genetic markers of obesity risk: stronger associations with body composition in overweight compared to normal-weight children. PLoS ONE 2011,6:e19057.

722

723

26. Mitchell JA, Hakonarson H, Rebbeck TR, Grant SFA. Obesity-susceptibility loci and the

724 tails of the pediatric BMI distribution. Obesity (Silver Spring) 2013, 21:1256-1260.

725

726 27. Williams PT. Quantile-dependent expressivity of postprandial lipemia. PLoS One.

727 2020;15:e0229495. doi:10.1371/journal.pone.0229495

728

729

28. Koenker R, Hallock KF. Quantile regression. J Economic Perspectives. 2001;15:143-56.

730

731 29. Gould WW. Quantile regression with bootstrapped standard errors. Stata Technical

732 Bulletin. 1992;9:19-21.

733 
734 30. Kannel WB, Feinleib M, McNamara PM, Garrison RJ, Castelli WP. An investigation of

735

736

737

738

739

740

741

742

743

744

745

746

747

748

749

750

751

752

753

754

755

756

757

758

759

760

761

762

763

764 coronary heart disease in families. The Framingham offspring study. Am J Epidemiol. 2006;110:281-90.

31. Splansky GL, Corey D, Yang Q, Atwood LD, Cupples LA, Benjamin EJ, D'Agostino RB Sr, Fox CS, Larson MG, Murabito JM, O'Donnell CJ, Vasan RS, Wolf PA, Levy D. The Third Generation Cohort of the National Heart, Lung, and Blood Institute's Framingham Heart Study: design, recruitment, and initial examination. Am J Epidemiol. 2007;165:1328-35. doi: 10.1093/aje/kwm021.

32. Falconer DS, Mackay TFC. Introduction to Quantitative Genetics (fourth ed.) Longmans Green, Harlow, Essex, UK 1996

33. Dehghan A, Dupuis J, Barbalic M, Bis JC, Eiriksdottir G, Lu C, Pellikka N, Wallaschofski H, Kettunen J, Henneman P, Baumert J, Strachan DP, Fuchsberger C, Vitart V, Wilson JF, Paré G, Naitza S, Rudock ME, Surakka I, de Geus EJ, Alizadeh BZ, Guralnik J, Shuldiner A, Tanaka T, Zee RY, Schnabel RB, Nambi V, Kavousi M, Ripatti S, Nauck M, Smith NL, Smith AV, Sundvall J, Scheet P, Liu Y, Ruokonen A, Rose LM, Larson MG, Hoogeveen RC, Freimer NB, Teumer A, Tracy RP, Launer LJ, Buring JE, Yamamoto JF, Folsom AR, Sijbrands EJ, Pankow J, Elliott P, Keaney JF, Sun W, Sarin AP, Fontes JD, Badola S, Astor BC, Hofman A, Pouta A, Werdan K, Greiser KH, Kuss O, Meyer zu Schwabedissen HE, Thiery J, Jamshidi Y, Nolte IM, Soranzo N, Spector TD, Völzke H, Parker AN, Aspelund T, Bates D, Young L, Tsui K, Siscovick DS, Guo X, Rotter JI, Uda M, Schlessinger D, Rudan I, Hicks AA, Penninx BW, Thorand B, Gieger C, Coresh J, Willemsen G, Harris TB, Uitterlinden AG, Järvelin MR, Rice K, Radke D, Salomaa V, Willems van Dijk K, Boerwinkle E, Vasan RS, Ferrucci L, Gibson QD, Bandinelli S, Snieder H, Boomsma DI, Xiao X, Campbell H, Hayward C, Pramstaller PP, van Duijn CM, Peltonen L, Psaty BM, Gudnason V, Ridker PM, Homuth G, Koenig W, Ballantyne CM, Witteman JC, Benjamin EJ, Perola M, Chasman DI. Meta-analysis of genome-wide association studies in $>80000$ subjects identifies multiple loci for C-reactive protein levels. Circulation. 2011;123(7):731-8. doi: 10.1161/CIRCULATIONAHA.110.948570. 
765

766 34. Agrawal A: CRP after 2004. Mol Immunol 2005, 42:927-930.

767

768 35. Danik JS, Ridker PM. Genetic determinants of C-reactive protein. Curr Atheroscler

769 Rep 2007;9:195-203

770

771 36. Shoamanesh A, Preis SR, Beiser AS, Vasan RS, Benjamin EJ, Kase CS, Wolf PA,

772 DeCarli C, Romero JR, Seshadri S. Inflammatory biomarkers, cerebral microbleeds, and

773

774 small vessel disease: Framingham Heart Study. Neurology. 2015;84:825-32. doi:

775

776

777 10.1212/WNL.0000000000001279.

37. Karlin S, Cameron EC, Williams PT. Sibling and parent-offspring correlation estimation with variable family size. Proc Natl Acad Sci USA. 1981;78:2664-8.

778

779

38. Winer BJ, Brown DR, Michels KM. 1991 Statistical principles in experimental design. 780 Third edition. McGraw-Hill New York.

781

782

783

39. NIH National Heart Lung, and Blood Institute Biologic Specimen and Data Repository Information Coordinating Center https://biolincc.nhlbi.nih.gov/home/ • (Accessed

784 June 29, 2020)

785

786

40. dbGaP genotypes and phenotypes. Framingham cohort. dbGaP Study Accession:

787 phs000007.v30.p11 https://www.ncbi.nlm.nih.gov/projects/gap/cgi-

788 bin/study.cgi?study id=phs000007.v30.p11 (Accessed June 29, 2020).

789

790 41. D'Aiuto F, Casas JP, Shah T, Humphries SE, Hingorani AD, Tonetti MS. C-reactive 791

792 protein $(+1444 \mathrm{C}>\mathrm{T})$ polymorphism influences CRP response following a moderate 793 inflammatory stimulus. Atherosclerosis. 2005;179:413-7. doi:

794 
795 42. Suk Danik J, Chasman DI, Cannon CP, Miller DT, Zee RY, Kozlowski P, Kwiatkowski

796

797

798

799

800

801

802

803

804

805

806

807

808

809

810

811

812

813

814

815

816

817

818

819

820

821

822

823

DJ, Ridker PM. Influence of genetic variation in the C-reactive protein gene on the inflammatory response during and after acute coronary ischemia. Ann Hum Genet. 2006;70:705-16. doi: 10.1111/j.1469-1809.2006.00272.x.

43. Szalai AJ, Wu J, Lange EM, McCrory MA, Langefeld CD, Williams A, Zakharkin SO, George V, Allison DB, Cooper GS, Xie F, Fan Z, Edberg JC, Kimberly RP. Singlenucleotide polymorphisms in the C-reactive protein (CRP) gene promoter that affect transcription factor binding, alter transcriptional activity, and associate with differences in baseline serum CRP level. J Mol Med (Berl). 2005;83(6):440-7. doi: 10.1007/s00109-0050658-0.

44. Cao H, Hegele RA. Human C-reactive protein (CRP) 1059G/C polymorphism. J Hum Genet 2000;54:100-1.

45. Gabay C, Kushner I. Acute-phase proteins and other systemic responses to inflammation. N Engl J Med. 1999;340:448-454.

46. Vickers MA, Green FR, Terry C, Mayosi BM, Julier C, Lathrop M, Ratcliffe PJ, Watkins $\mathrm{HC}$, Keavney B. Genotype at a promoter polymorphism of the interleukin- 6 gene is associated with baseline levels of plasma C-reactive protein. Cardiovasc Res. 2002;53:1029-34. doi: 10.1016/s0008-6363(01)00534-x.

47. Ferrari SL, Ahn-Luong L, Garnero P, Humphries SE, Greenspan SL. Two promoter polymorphisms regulating interleukin-6 gene expression are associated with circulating levels of C-reactive protein and markers of bone resorption in postmenopausal women. J Clin Endocrinol Metab. 2003 ;88:255-9. doi: 10.1210/jc.2002-020092. 
824 48. Wilson AG, Symons JA, McDowell TL, McDevitt HO, Duff GW. Effects of a

825 polymorphism in the human tumor necrosis factor alpha promoter on transcriptional

826 activation. Proc Natl Acad Sci U S A 1997, 94:3195-3199.

827

828 49. Plutzky J. Inflammatory pathways in atherosclerosis and acute coronary syndromes. Am J

829 Cardiol 2001;88:10K-15K.

830

831

50. Judson R, Brain C, Dain B, Windemuth A, Ruano G, Reed C. New and confirmatory

832 evidence of an association between APOE genotype and baseline C-reactive protein

833 in dyslipidemic individuals. Atherosclerosis. 2004;177:345-51

834

835

51. Hubacek JA, Peasey A, Pikhart H, Stavek P, Kubinova R, Marmot M, Bobak M. APOE

836

837 polymorphism and its effect on plasma C-reactive protein levels in a large general

838 population sample. Hum Immunol. 2010;71:304-8. doi:

839

840

52. Naudé PJW, Roest AM, Stein DJ, de Jonge P, Doornbos B. Anxiety disorders and CRP in 841

842 a population cohort study with 54,326 participants: The LifeLines study. World J Biol

843 Psychiatry. 2018;19:461-470. doi: 10.1080/15622975.2018.1433325.

843

844

53. Chasman DI, Kozlowski P, Zee RY, Kwiatkowski DJ, Ridker PM. Qualitative and 845 quantitative effects of APOE genetic variation on plasma C-reactive protein, LDL-

846

847 cholesterol, and apoE protein. Genes Immun. 2006;7:211-9. doi:

848

849

54. Eiriksdottir G, Smith AV, Aspelund T, Hafsteinsdottir SH, Olafsdottir E, Launer LJ,

850 10.1038/sj.gene.6364289.

851 Harris TB, Gudnason V. The interaction of adiposity with the CRP gene affects CRP 852 levels: age, gene/environment susceptibilty-Reykjavik study. Int J Obes (Lond).

853 2009;33:267-72. doi: 10.1038/ijo.2008.274. 
854 55. Fried SK, Bunkin DA, Greenberg AS. Omental and subcutaneous adipose tissues of obese 855 subjects release interleukin-6: depot difference and regulation by glucocorticoid. J Clin 856 Endocrinol Metab 1998;83:847-850.

857

858 56. Forouhi NG, Sattar N, McKeigue PM. Relation of C-reactive protein to body fat 859 distribution and features of the metabolic syndrome in Europeans and South Asians. Int J

860 Obes Relat Metab Disord 2001;9:1327-1331.

861

862

57. Visser M, Bouter LM, McQuillan GM, Wener MH, Harris TB. Elevated C-reactive

863 protein levels in overweight and obese adults. JAMA 1999;282:2131-2135.

864

865

58. Selvin E, Paynter NP, Erlinger TP. The effect of weight loss on C-reactive protein: a

866 systematic review. Arch Intern Med. 2007;167:31-9. doi: 10.1001/archinte.167.1.31.

867

868

59. Friedlander Y, Kark JD, Sinnreich R, Tracy RP, Siscovick DS. Fibrinogen and CRP in 869 Israeli families: genetic and environmental sources of concentrations and longitudinal

870 changes. Atherosclerosis. 2006;189:169-77. doi: 10.1016/j.atherosclerosis.2005.11.030.

871

872

60. Farup PG, Rootwelt H, Hestad K. APOE - a genetic marker of comorbidity in subjects

873

874 with morbid obesity. BMC Med Genet. 2020;21:146. doi: 10.1186/s12881-020-

875

876

61. Pramudji H, Demes CM, Dewi K, Tasmini T, Ahmad HS. Association of $-174 \mathrm{G}>\mathrm{C}$

877 interleukin-6 gene polymorphism with interleukin-6 and c-reactive protein levels and

878

879 obesity: A case-control study among people/residents of Western Indonesia. Med J

880

881

62. Teng MS, Hsu LA, Wu S, Chang HH, Chou HH, Ko YL. Association between C-reactive 882

883 protein gene haplotypes and C-reactive protein levels in Taiwanese: interaction with obesity. Atherosclerosis. 2009;204:e64-e69. doi:10.1016/j.atherosclerosis.2008.10.034

884 
885 63. Todendi PF, Possuelo LG, Klinger EI, Reuter CP, Burgos MS, Moura DJ, Fiegenbaum M, 886 Valim AR. Low-grade inflammation markers in children and adolescents: Influence of 887 888 anthropometric characteristics and CRP and IL6 polymorphisms. Cytokine. 2016

889

890

891

892

893 Dec;88:177-183. doi: 10.1016/j.cyto.2016.09.007.

894

895

65. Lowe GD, Yarnell JW, Rumley A, Bainton D, Sweetnam PM. C-reactive protein, fibrin

896

897

898

64. Wang TN, Wu CC, Huang MS, Wang CC, Huang CC, Wang TH, Lien TC, Ko YC, Lin MC. The polymorphisms of C-reactive protein gene modify the association between central obesity and lung function in taiwan asthmatics. Scand J Immunol. 2011;74:482-8. doi: 10.1111/j.1365-3083.2011.02599.x..

899

900

66. Retterstol L, Eikvar L, Berg K. A twin study of C-Reactive Protein compared to other risk 901

902 factors for coronary heart disease. Atherosclerosis. 2003;169:279-82. doi: 10.1016/s0021-

903

904

67. Luetragoon T, Rutqvist LE, Tangvarasittichai O, Andersson BÅ, Löfgren S,

905

906

907 9150(03)00192-8.

908

909

68. Shin KK, Jang Y, Koh SJ, Chae JS, Kim OY, Park S, Choi D, Shin DJ, Kim HJ, Lee JH.

910

911

912 Usuwanthim K, Lewin NL. Interaction among smoking status, single nucleotide polymorphisms and markers of systemic inflammation in healthy individuals. Immunology. 2018;154:98-103. doi: 10.1111/imm.12864.

\section{3}

914 69. Gander ML, Fischer JE, Maly FE, von Känel R. Effect of the G-308A polymorphism of 915 Influence of the IL-6 $-572 \mathrm{C}>\mathrm{G}$ polymorphism on inflammatory markers according to cigarette smoking in Korean healthy men. Cytokine. 2007;39:116-22. doi:

10.1016/j.cyto.2007.06.005.

PeerJ reviewing PDF | (2020:10:53970:1:1:CHECK 8 Jan 2021) 
916 and C-reactive protein in smokers: a cross-sectional study. BMC Cardiovasc Disord.

917 2004;4:17. doi:10.1186/1471-2261-4-17

918

919 70. Brull DJ, Serrano N, Zito F, Jones L, Montgomery HE, Rumley A, Sharma P, Lowe GD, 920 World MJ, Humphries SE, Hingorani AD. Human CRP gene polymorphism influences

921 CRP levels: implications for the prediction and pathogenesis of coronary heart disease.

$922 \quad$ Arterioscler Thromb Vasc Biol. 2003;23:2063-9. doi:

923 10.1161/01.ATV.0000084640.21712.9C.

924

925 71. Esposito K, Marfella R, Ciotola M, Di Palo C, Giugliano F, Giugliano G, D'Armiento M,

926 D'Andrea F, Giugliano D. Effect of a mediterranean-style diet on endothelial dysfunction 927 and markers of vascular inflammation in the metabolic syndrome: a randomized trial.

928 JAMA. 2004;292:1440-6. doi: 10.1001/jama.292.12.1440.

929

930 72. Keramat L, Sadrzadeh-Yeganeh H, Sotoudeh G, Zamani E, Eshraghian M, Mansoori A, 931 Koohdani F. Apolipoprotein A2 -265 T $>$ C polymorphism interacts with dietary fatty acids 932 intake to modulate inflammation in type 2 diabetes mellitus patients. Nutrition.

933 2017;37:86-91. doi: 10.1016/j.nut.2016.12.012.

934

935

936

73. Carvalho-Wells AL, Jackson KG, Lockyer S, Lovegrove JA, Minihane AM. APOE

937 genotype influences triglyceride and C-reactive protein responses to altered dietary fat

938

939 74. Gomez-Delgado F, Garcia-Rios A, Alcala-Diaz JF, Rangel-Zuñiga O, Delgado-Lista J, 940 Yubero-Serrano EM, Lopez-Moreno J, Tinahones FJ, Ordovas JM, Garaulet M, Lopez-

941 Miranda J, Perez-Martinez P. Chronic consumption of a low-fat diet improves

942

943 cardiometabolic risk factors according to the CLOCK gene in patients with coronary heart 944 
945 75. Zee RY, Ridker PM. Polymorphism in the human C-reactive protein (CRP) gene, plasma

946 concentrations of CRP, and the risk of future arterial thrombosis. Atherosclerosis

2002;162;217-219.

948

949 76. Kovacs A, Green F, Hansson LO, Lundman P, Samnegård A, Boquist S, Ericsson CG,

950

951

952

953

Watkins H, Hamsten A, Tornvall P. A novel common single nucleotide polymorphism in

954

955

77. Ben-Assayag E, Shenhar-Tsarfaty S, Bova I, Berliner S, Shopin L, Peretz H, Usher S,

956

957

958 the promoter region of the C-reactive protein gene associated with the plasma concentration of C-reactive protein. Atherosclerosis. 2005;178:193-8. doi:

10.1016/j.atherosclerosis.2004.08.018.

959

960

961

78. Kolb H, Mandrup-Poulsen T: An immune origin of type 2 diabetes? Diabetologia Shapira I, Bornstein NM. Triggered C-reactive protein (CRP) concentrations and the CRP gene $-717 \mathrm{~A}>\mathrm{G}$ polymorphism in acute stroke or transient ischemic attack. Eur J Neurol. 2007;14:315-20. doi: 10.1111/j.1468-1331.2006.01661.x

962

963

79. Pradhan AD, Manson JE, Rifai N, Buring JE, Ridker PM. C-reactive protein, interleukin 964 48:1038-1050, 2005

\section{5}

966

967

80. Qi L, Rifai N, Hu FB. Interleukin-6 receptor gene variations, plasma interleukin-6 levels, 968

969

970

971

972 6, and risk of developing type 2 diabetes mellitus. JAMA 286:327-334, 2001

\section{3}

974 82. Eldridge RC, Wentzensen N, Pfeiffer RM, Brinton LA, Hartge P, Guillemette C, Kemp 975

81. Libra M, Signorelli SS, Bevelacqua Y, Navolanic PM, Bevelacqua V, Polesel J, Talamini R, Stivala F, Mazzarino MC, Malaponte G. Analysis of G(-174)C IL-6 polymorphism and plasma concentrations of inflammatory markers in patients with type 2 diabetes and peripheral arterial disease. J Clin Pathol. 2006;59:211-5. doi: 10.1136/jcp.2004.025452. 
976 interacting mechanisms of obesity-related disease. Cancer Causes Control. 2020;31:309-

977 320. doi: 10.1007/s10552-020-01280-6.

978

979 83. Nazmi A, Victora CG. Socioeconomic and racial/ethnic differentials of C-reactive protein

980 levels: A systematic review of population-based studies. BMC Public Health 2007; 7:212.

981

982

84. Shah T, Newcombe P, Smeeth L, Addo J, Casas JP, Whittaker J, Miller MA, Tinworth L, 983

984 Jeffery S, Strazzullo P, Cappuccio FP, Hingorani AD. Ancestry as a determinant of mean 985 population C-reactive protein values: implications for cardiovascular risk prediction. Circ 986

987

85. Reiner AP, Beleza S, Franceschini N, Auer PL, Robinson JG, Kooperberg C, Peters U, 988

989 Tang H. Genome-wide association and population genetic analysis of C-reactive 990 protein in African American and Hispanic American women. Am J Hum Genet.

991

992

86. Wu J, Pankow JS, Tracy RP, North KE, Myers RH, Feitosa ME, Province MA, Borecki IB. 993 994 995 2012;91:502-12. doi: 10.1016/j.ajhg.2012.07.023. A QTL on 12q influencing an inflammation marker and obesity in white women: the NHLBI Family Heart Study. Obesity (Silver Spring). 2009;17:525-31. doi:

996

997 87. Wypasek E, Stepien E, Kot M, Plicner D, Kapelak B, Sadowski J, Undas A. Fibrinogen 998 10.1038/oby.2008.556..

1001

88. Wypasek E, Undas A, Sniezek-Maciejewska M, Kapelak B, Plicner D, Stepien E, Sadowski J. The increased plasma C-reactive protein and interleukin-6 levels in patients undergoing coronary artery bypass grafting surgery are associated with the interleukin-6-174G > C gene polymorphism. Ann Clin Biochem. 2010;47:343-9. doi: 10.1258/acb.2010.090305. 
1008 89. Mathew JP, Podgoreanu MV, Grocott HP, White WD, Morris RW, Stafford-Smith M,

1009 Mackensen GB, Rinder CS, Blumenthal JA, Schwinn DA, Newman MF; PEGASUS

1010

1011 Investigative Team. Genetic variants in P-selectin and C-reactive protein influence susceptibility to cognitive decline after cardiac surgery. J Am Coll Cardiol. 2007;49:1934-

1013

1014 90. Perry TE, Muehlschlegel JD, Liu KY, Fox AA, Collard CD, Body SC, Shernan SK; 1015

1016

1017 42. doi: 10.1016/j.jacc.2007.01.080.

1018

1019

91. D’Aiuto F, Nibali L, Mohamed-Ali V, Vallance P, Tonetti MS. Periodontal therapy: a 1020

1021 novel non-drug-induced experimental model to study human inflammation. J Periodontal Res 2004;39:294-9.

1022

1023

92. Motoyama S, Miura M, Hinai Y, Maruyama K, Usami S, Nakatsu T, Saito H, Minamiya

1024 Y, Suzuki T, Ogawa J. C-reactive protein 1059G $>$ C genetic polymorphism influences

1025 serum C-reactive protein levels after esophagectomy in patients with thoracic esophageal

1026 cancer. J Am Coll Surg. 2009;209:477-83. doi: 10.1016/j.jamcollsurg.2009.06.365.

1027

1028

93. Mölkänen T, Rostila A, Ruotsalainen E, Alanne M, Perola M, Järvinen A. Genetic

1029

1030 polymorphism of the C-reactive protein (CRP) gene and a deep infection focus determine

1031 maximal serum CRP level in Staphylococcus aureus bacteremia. Eur J Clin Microbiol

1031 Infect Dis. 2010;29:1131-1137. doi:10.1007/s10096-010-0978-Z

1032

1033

1034 94. Hampe J, Shaw SH, Saiz R, Leysens N, Lantermann A, Mascheretti S, Lynch NJ, 1035 MacPherson AJ, Bridger S, van Deventer S, Stokkers P, Morin P, Mirza MM, Forbes A, 
1037

1038

1039

1040

1041

1042

1043

1044

1045

1046

1047

1048

1049

1050

1051

1052

1053

1054

1055

1056

1057

1058

1059

1060

1061

1062

1063

1064

1065

1066

1067

disease to human chromosome 6p. Am J Hum Genet. 1999;65:1647-55. doi: 10.1086/302677. P

95. Liaquat A, Asifa GZ, Zeenat A, Javed Q. Polymorphisms of tumor necrosis factor-alpha and interleukin-6 gene and C-reactive protein profiles in patients with idiopathic dilated cardiomyopathy. Ann Saudi Med. 2014;34:407-14. doi: 10.5144/02564947.2014.407.

96. Kim JJ, Yun SW, Yu JJ, Yoon KL, Lee KY, Kil HR, Kim GB, Han MK, Song MS, Lee HD, Byeon JH, Sohn S, Hong YM, Jang GY, Lee JK; Korean Kawasaki Disease Genetics Consortium. Common variants in the CRP promoter are associated with a high Creactive protein level in Kawasaki disease. Pediatr Cardiol. 2015;36:438-44. doi: 10.1007/s00246-014-1032-1.

97. Wu S, Hsu LA, Cheng CF, Teng MS, Chou HH, Lin H, Chang PY, Ko YL. Effect of obesity on the association between ATF3 gene haplotypes and C-reactive protein level in Taiwanese. Clin Chim Acta. 2011;;412:1026-31. doi: 10.1016/j.cca.2011.02.011.

98. Hsu LA, Ko YL, Teng MS, Wu S, Chou HH, Chang PY, Chang HH. Effect of obesity on the association between common variations in the HNF1A gene region and C-reactive protein level in Taiwanese. Clin Chim Acta. 2011;412:725-9. doi:

10.1016/j.cca.2010.12.027.

99. Eklund C, Nenonen A, Kukkonen-Harjula K, Borg P, Fogelholm M, Laine S, Huhtala H, Lehtimäki T, Hurme M. Association of the IL6-174(G/C) polymorphism with C-reactive protein concentration after weight loss in obese men. Eur Cytokine Netw. 2006;17:131-5.

100. Shangwei Z, Yingqi W, Jiang X, Zhongyin W, Juan J, Dafang C, Yonghua H, Wei G. Serum High-Sensitive C-Reactive Protein Level and CRP Genetic Polymorphisms Are Associated with Abdominal Aortic Aneurysm. Ann Vasc Surg. 2017;45:186-192. doi: 10.1016/j.avsg.2017.05.024.

Peer) reviewing PDF | (2020:10:53970:1:1:CHECK 8 Jan 2021) 
1068

1069 101. Yaffe K, Lindquist K, Penninx BW, Simonsick EM, Pahor M, Kritchevsky S, Launer L, $1070 \quad$ Kuller L, Rubin S, Harris T. Inflammatory markers and cognition in well-functioning 1071 African-American and white elders. Neurology. 2003;61:76-80. doi:

1072 10.1212/01.wnl.0000073620.42047.d7.

1073

1074 102. Zaciragic A, Lepara O, Valjevac A, Arslanagic S, Fajkic A, Hadzovic-Dzuvo A, Avdagic 1075 N, Alajbegovic A, Mehmedika-Suljic E, Coric G. Elevated serum C-reactive protein 1076 concentration in Bosnian patients with probable Alzheimer's disease. J Alzheimers Dis. 2007;12:151-6. doi: 10.3233/jad-2007-12204. 
1079

1080

Figure legends

1081

1082 Figure 1. A) Offspring-parent regression slopes $\left(\beta_{\mathrm{OP}}\right)$ for selected quantiles of the offspring's 1083 untransformed CRP concentrations from 6144 offspring-parent pairs, with corresponding 1084 estimates of heritability $\left(h^{2}=2 \beta_{\mathrm{OP}} /\left(1+\mathrm{r}_{\text {spouse }}\right)\right.$ [32], where the correlation between spouses was $1085 \mathrm{r}_{\text {spouse }}=-0.0013$. The slopes became progressively greater (i.e., steeper) with increasing quantiles 1086 of the CRP distribution. B) The selected quantile-specific regression slopes were included with 1087 those of other quantiles to create the quantile-specific heritability function in the lower panel.

1088 Significance of the linear, quadratic and cubic trends and the 95\% confidence intervals (shaded 1089 region) determined by 1000 bootstrap samples. C) Quantile-specific full-sib regression slopes $1090\left(\beta_{\mathrm{FS}}\right)$ from 5703 full-sibs in 2036 sibships, with corresponding estimates of heritability as 1091 calculated by $h^{2}=\left\{\left(8 \mathrm{r}_{\text {spouse }} \beta_{\mathrm{FS}}+1\right)^{0.5}-1\right\} /\left(2 \mathrm{r}_{\text {spouse }}\right)$ [32].

1092

Figure 2. A) Quantile-specific offspring-parent $\left(\beta_{\mathrm{OP}}\right)$ for the offspring's logarithmically 1094 transformed CRP concentrations with corresponding estimates of heritability [32], where the 1095 correlation between spouses was $r_{\text {spouse }}=0.0482$. B) full-sib regression slopes $\left(\beta_{\mathrm{FS}}\right)$ for

1096 logarithmically transformed CRP concentrations.

1097

1098 Figure 3. Simple regression analysis of showing larger genotype differences associated with 1099 higher estimated average CRP response for the data presented in: A) Farup et al.'s [60] 2020 1100 report on the APOE CRP differences (non-carriers minus carriers of $\varepsilon 4$-allele) in morbidly obese 1101 patients losing weight; B) Perry et al.'s [90] 2009 report on the rs3091244 CRP difference (T1102 allele carrier minus noncarrier) post CABG surgery $\left(\mathrm{P}_{\text {linear }}=0.08\right)$; C) Perry et al.'s [90] 2009 1103 report on the rs1800947 CRP difference (GG homozygotes minus C-allele carrier) post CABG 1104 surgery $\left(\mathrm{P}_{\text {linear }}=0.11\right)$; D) Brull et al.'s [70] 2003 report on the rs 1130864 CRP difference (TT 1105 homozygotes minus $\mathrm{C}$-allele carriers) pre- and post $\mathrm{CABG}$ surgery $\left(\mathrm{P}_{\text {linear }}=0.02\right)$; E) D'Aiuto et 1106 al.'s [41] 2005 report on the rs1 130864 CRP difference (TT homozygotes minus C-allele 1107 carriers) following periodontal intensive therapy $\left(\mathrm{P}_{\text {linear }}=0.002\right)$; F) Motoyama et al.'s [92] 2009 1108 report on the rs 1800947 CRP difference (GG homozygotes minus C-allele carriers) following 1109 esophagectomy surgery $\left(\mathrm{P}_{\text {linear }}=0.07\right)$. 
1110

1111 Figure 4. Precision medicine perspective of genotype-specific CRP differences (histogram

1112 inserts) vs. quantile-dependent expressivity perspective (line graphs showing larger genetic

1113 effect size when average CRP concentrations were high) for the data presented in: A) Pramudji

1114 et al. [61] of the CRP difference between obese and non-obese subjects by the $-174 \mathrm{G}>\mathrm{C} I L-6$

1115 polymorphism; B) Teng et al.'s [62] 2009 report on the CRP difference between obese and non-

1116 obese subjects by the rs2794521 genotypes $\left(\mathrm{P}_{\text {interaction }}=0.034\right)$; C) Teng et al.'s [62] 2009 report

1117 on the CRP difference between obese and non-obese subjects by the rs 1800947 genotypes

1118 ( $\left.\mathrm{P}_{\text {interaction }}=0.02\right)$; D) Teng et al.'s [62] 2009 report on the CRP difference between obese and

1119 non-obese subjects by the rs1205 genotypes $\left(\mathrm{P}_{\text {interaction }}=0.02\right)$; E) Luetragoon et al.'s [67] 2017

1120 report on the CRP difference between smokers and nonsmokers by CRP 1800947 genotypes; F)

1121 Shin et al.'s [68] 2007 report on the CRP difference (mg/dL) between smokers and nonsmokers

1122 by $C R P$ rs 1800796 genotypes. * Except where noted.

1123

1124 Figure 5. Precision medicine perspective of genotype-specific CRP differences (histogram

1125 inserts) vs. quantile-dependent expressivity perspective (line graphs showing larger genetic

1126 effect size when average CRP concentrations were high) for the data presented in: A) Gander et

1127 al.'s [69] 2004 report on the CRP difference between smokers and nonsmokers by CRP

1128 rs1800629; B) Brull et al.’s [70] 2003 reported on the effect of 48-hour military endurance

1129 exercise on CRP concentrations by rs1130864 genotypes; C) Keramet et al.'s [72] 2017 report on

1130 the affect of monounsaturated fat intake on CRP concentrations by APOA2 rs5082 genotypes; D)

1131 Carvalho-Wells et al.'s [73] 2012 report on the effect of a high fat diet by APOE isoform; E)

1132 Gomez-Delgado et al.'s [74] 2015 report on the affect of a lowfat diet by CLOCK rs4580704

1133 genotypes; F) Zee and Ridker's [75] report on the CRP difference between men experiencing vs.

1134 not experiencing their first arterial thrombosis during 8.6 year follow-up by CRP rs 1800947

1135 genotypes.

1136

1137 Figure 6. Precision medicine perspective of genotype-specific CRP differences (histogram

1138 inserts) vs. quantile-dependent expressivity perspective (line graphs showing larger genetic

1139 effect size when average CRP concentrations were high) for the data presented in: A) Kovacs et

1140 al. [76] 2005 reported on the effect of myocardial infarction by CRP rs3091244 genotypes cross-

Peer) reviewing PDF | (2020:10:53970:1:1:CHECK 8 Jan 2021) 
1141 sectionally; B) Qi et al.'s [80] 2007 report on the effect of T2DM by interleukin-6 receptor 1142 (IL6R) rs8192284 genotypes $\left(\mathrm{P}_{\text {interaction }}=0.03\right)$; C) Libra et al.'s [81] 2006 report on the CRP 1143 difference between T2DM with (PAD+) and without (PAD-) peripheral arterial disease by IL-6

1144 G(-174)C rs1800795 genotypes; D) Wypasek et al. [87] 2012 reported on the effects of coronary 1145 artery bypass grafting (CABG) surgery on CRP by fibrinogen beta-chain $(F G B)-148 \mathrm{C}>\mathrm{T}$ 1146 genotypes (rs1800787); E) Wypasek et al. [88] 2010 reported on the effects of CABG surgery on 1147 CRP by -174G>C IL-6 (rs1800795) genotypes; F) Mathew et al. [89] 2007 report on the effects 1148 of $\mathrm{CABG}$ with cardiopulmonary bypass by $C R P+1059 \mathrm{G}>\mathrm{C}$ (rs1800947) genotypes. * Except 1149 where noted.

1150

1151 Figure 7. Precision medicine perspective of genotype-specific CRP differences (histogram 1152 inserts) vs. quantile-dependent expressivity perspective (line graphs showing larger genetic 1153 effect size when average CRP concentrations were high) for the data presented in: A) Suk Danil 1154 et al. [42] 2006 report on the effect of acute coronary syndrome by $C R P$ rs3091244 genotypes; 1155 B) Suk Danil et al. [42] 2006 report on the effect of acute coronary syndrome by CRP rs 1800947 1156 genotypes; and C) Suk Danil et al. [42] 2006 report on the effect of acute coronary syndrome by $1157 C R P$ rs1205 genotypes; D) Kovacs et al's [76] 2005 report on the effect of myocardial infarction 1158 (MI) by CRP rs3091244 genotypes longitudinally; E) Mölkänen et al. [93] 2010 reported on the 1159 effect of Staphylococcus aureus bacteremia by rs3091244 genotypes; F) Ammitzboll et al. [7] 11602014 report on the effect of early chronic rheumatoid arthritis by CRP rs1205.

1161

1162 Figure 8. Precision medicine perspective of genotype-specific CRP differences (histogram 1163 inserts) vs. quantile-dependent expressivity perspective (line graphs showing larger genetic 1164 effect size when average CRP concentrations were high) for the data presented in: A) Wielińska 1165 et al. [8] 2020 report on the effect of anti-TNF treatment by $R A N K$ rs8086340 genotypes; B) 1166 Wielińska et al.'s [8] 2020 report on the effect of anti-TNF treatment by RANKL rs7325635 1167 genotypes; C) Vatay et al's [10] 2003 report on the CRP difference between active phase 1168 inflammatory bowel disease and healthy controls by tumor necrosis factor alpha (TNF- $\alpha$ ) G1169 308A (rs1800629) promoter polymorphism; D) Xu et al.'s [9] 2020 report on the effect of 1170 etanercept treatment in Ankylosing spondylitis patients by CRP rs3091244 genotypes; E) 1171 Liaquat et al. [95] on the effect of idiopathic dilated cardiomyopathy by TNF- $\alpha$ (rs 1800629) - 
$1172308 \mathrm{G}>$ A genotypes; F) Liaquat et al. [95] on the effect of idiopathic dilated cardiomyopathy by 1173 IL-6 rs1800795 (-174 G>C) genotypes.

1174

1175 Figure 9. Precision medicine perspective of genotype-specific CRP differences (histogram 1176 inserts) vs. quantile-dependent expressivity perspective (line graphs showing larger genetic 1177 effect size when average CRP concentrations were high) for the data presented in Kim et al.'s 1178 [96] 2014 report on the effect of Kawasaki disease by CRP promoter rs 12068753 genotypes. 1179 
Table $\mathbf{1}$ (on next page)

Table 1. Sample characteristics 
1

2

3

Table 1. Sample characteristics*

\begin{tabular}{|c|c|c|c|c|}
\hline & \multicolumn{2}{|c|}{ Males } & \multicolumn{2}{|c|}{ Females } \\
\hline & $\begin{array}{l}\text { Offspring } \\
\text { Cohort }\end{array}$ & $\begin{array}{c}\text { Third } \\
\text { generation } \\
\text { cohort }\end{array}$ & $\begin{array}{c}\text { Offspring } \\
\text { Cohort }\end{array}$ & $\begin{array}{c}\text { Third } \\
\text { generation } \\
\text { cohort }\end{array}$ \\
\hline Sample size & 1232 & 1851 & 1340 & 2108 \\
\hline Age, years & $56.54(8.74)$ & $40.42(8.72)$ & $55.64(9.10)$ & $39.99(8.77)$ \\
\hline $\mathrm{BMI}, \mathrm{kg} / \mathrm{m}^{2}$ & $28.08(3.90)$ & $28.43(4.79)$ & $26.65(5.22)$ & $26.50(6.11)$ \\
\hline Waist/ht & $0.58(0.06)$ & $0.56(0.07)$ & $0.56(0.09)$ & $0.55(0.10)$ \\
\hline CRP mg/L-all & $3.58(5.83)$ & $2.15(3.12)$ & $3.84(4.97)$ & $3.05(4.57)$ \\
\hline Waist/ht $1^{\text {st }}$ tertile & $3.25(7.91)$ & $1.34(2.60)$ & $2.63(3.72)$ & $1.37(2.32)$ \\
\hline Waist/ht $2^{\text {nd }}$ tertile & $3.16(4.54)$ & $1.79(2.53)$ & $3.34(3.37)$ & $2.58(3.97)$ \\
\hline Waist/ht $3^{\text {rd }}$ tertile & $4.22(5.36)$ & $3.26(3.79)$ & $5.64(6.55)$ & $5.23(5.81)$ \\
\hline
\end{tabular}

4 


\section{Figure 1}

Quantile-specific offspring-parent $\left(\beta_{\mathrm{OP}}\right)$ and full-sib regression slopes $\left(\beta_{\mathrm{FS}}\right)$ for untransformed CRP concentrations

Figure 1. A) Offspring-parent regression slopes ( $\beta_{\mathrm{op}}$ ) for selected quantiles of the offspring's untransformed CRP concentrations from 6144 offspring-parent pairs, with corresponding estimates of heritability $\left(h^{2}=2 \beta_{\mathrm{op}} /\left(1+r_{\text {spouse }}\right)\right.$ [32], where the correlation between spouses was $r_{\text {spouse }}=-0.0013$. The slopes became progressively greater (i.e., steeper) with increasing quantiles of the CRP distribution. B) The selected quantile-specific regression slopes were included with those of other quantiles to create the quantile-specific heritability function in the lower panel. Significance of the linear, quadratic and cubic trends and the $95 \%$ confidence intervals (shaded region) determined by 1000 bootstrap samples. C) Quantilespecific full-sib regression slopes $\left(\beta_{\mathrm{FS}}\right.$ ) from 5703 full-sibs in 2036 sibships, with corresponding estimates of heritability as calculated by $h^{2}=\left\{\left(8 r_{\text {spouse }} \beta_{\mathrm{Fs}}+1\right)^{0.5}-1\right\} /\left(2 r_{\text {spouse }}\right)[32]$. 

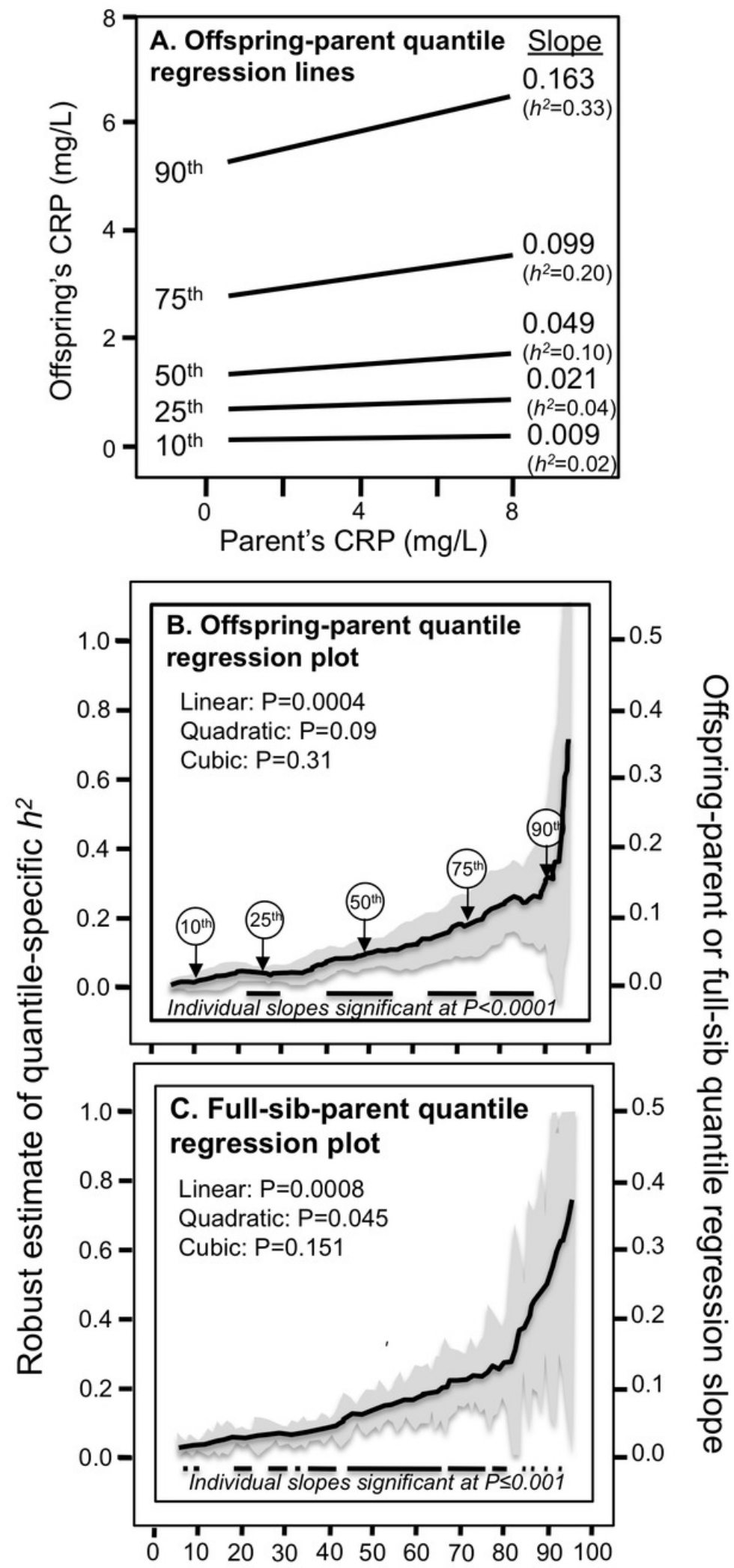

Percentiles of the offspring's or full sibs'

CRP distribution 


\section{Figure 2}

Figure 2. Quantile-specific offspring-parent $\left(\beta_{\mathrm{OP}}\right)$ and full-sib regression slopes $\left(\beta_{\mathrm{FS}}\right)$ for the offspring's logarithmically transformed CRP concentrations

Figure 2. A) Quantile-specific offspring-parent ( $\beta_{\mathrm{OP}}$ ) for the offspring's logarithmically transformed CRP concentrations with corresponding estimates of heritability [32], where the correlation between spouses was $r_{\text {spouse }}=0.0482$. B) full-sib regression slopes $\left(\beta_{F S}\right)$ for logarithmically transformed CRP concentrations. 

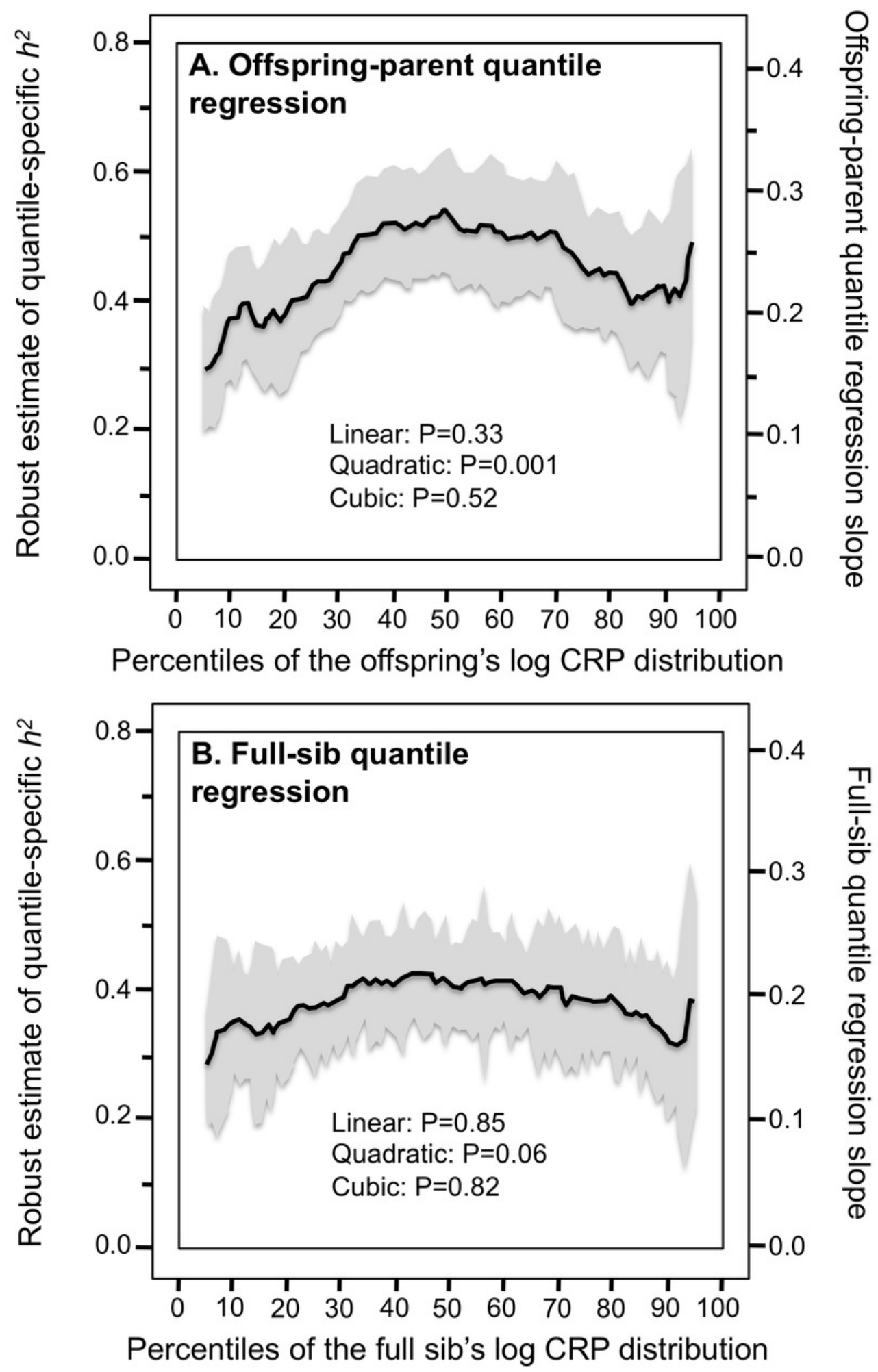


\section{Figure 3}

Simple regression analysis of showing larger genotype differences associated with higher estimated average CRP response

Simple regression analysis of showing larger genotype differences associated with higher estimated average CRP response for the data presented in: A) Farup et al.'s [60] 2020 report on the APOE CRP differences (non-carriers minus carriers of $\varepsilon 4$-allele) in morbidly obese patients losing weight; B) Perry et al.'s [90] 2009 report on the rs3091244 CRP difference (Tallele carrier minus noncarrier) post CABG surgery ( $\left.P_{\text {linear }}=0.08\right)$; C) Perry et al.'s [90] 2009 report on the rs 1800947 CRP difference (GG homozygotes minus C-allele carrier) post CABG surgery $\left.\left(P_{\text {linear }}=0.11\right) ; D\right)$ Brull et al.'s [70] 2003 report on the rs1130864 CRP difference ( $T T$ homozygotes minus $C$-allele carriers) pre- and post CABG surgery $\left(P_{\text {linear }}=0.02\right)$; E) D'Aiuto et al.'s [41] 2005 report on the rs1130864 CRP difference (TT homozygotes minus C-allele carriers) following periodontal intensive therapy $\left.\left(P_{\text {linear }}=0.002\right) ; F\right)$ Motoyama et al.'s [92] 2009 report on the rs 1800947 CRP difference (GG homozygotes minus C-allele carriers) following esophagectomy surgery $\left(P_{\text {linear }}=0.07\right)$. 

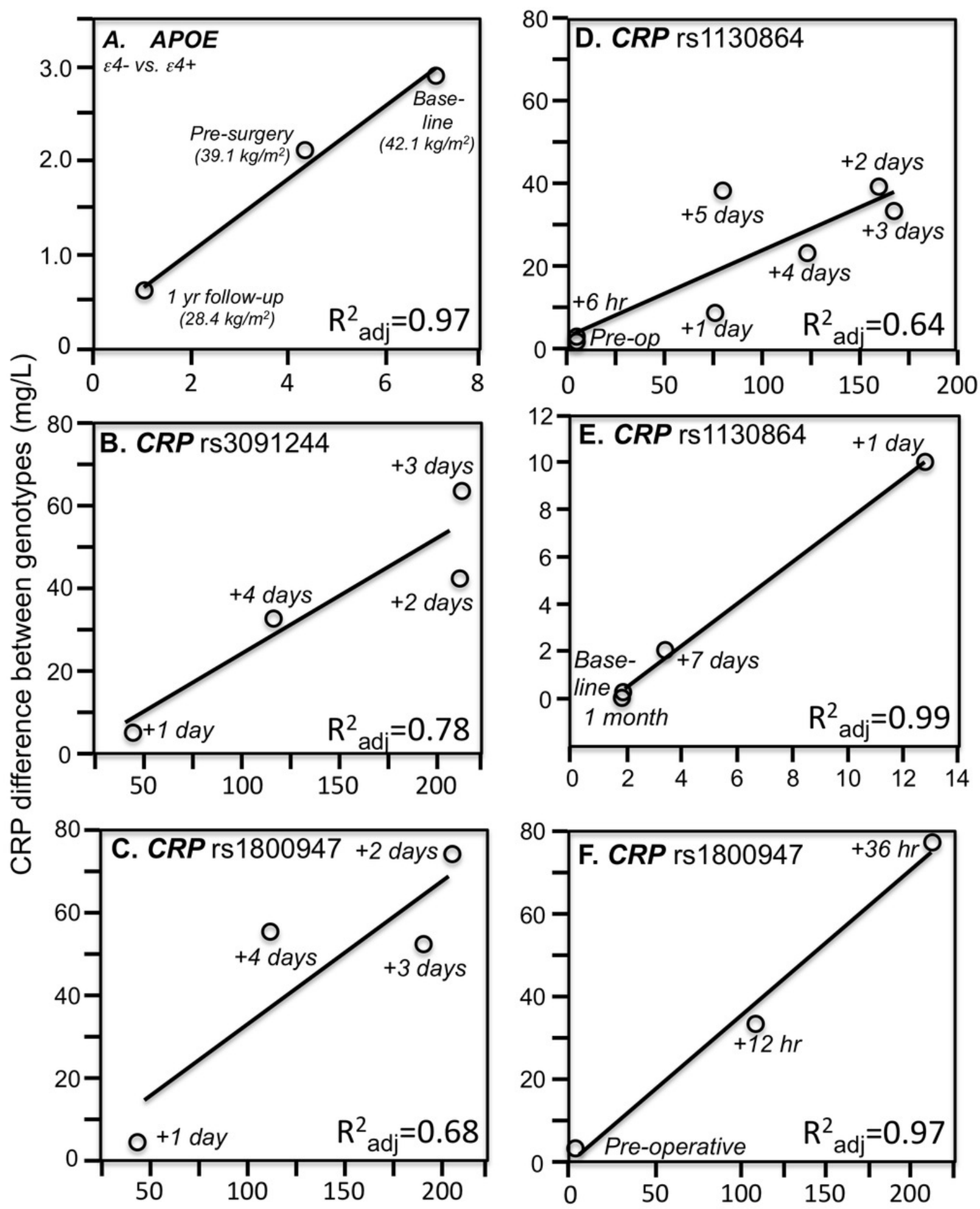

Average median CPR concentration (mg/L) 


\section{Figure 4}

Precision medicine perspective of genotype-specific CRP differences (histogram inserts) vs. quantile-dependent expressivity perspective (line graphs).

Precision medicine perspective of genotype-specific CRP differences (histogram inserts) vs. quantile-dependent expressivity perspective (line graphs showing larger genetic effect size when average CRP concentrations were high) for the data presented in: A) Pramudji et al. [61] of the CRP difference between obese and non-obese subjects by the -174 G>C IL-6 polymorphism; B) Teng et al.'s [62] 2009 report on the CRP difference between obese and non-obese subjects by the rs2794521 genotypes $\left.\left(P_{\text {interaction }}=0.034\right) ; C\right)$ Teng et al.'s [62] 2009 report on the CRP difference between obese and non-obese subjects by the rs 1800947 genotypes ( $\left.\left.P_{\text {interaction }}=0.02\right) ; D\right)$ Teng et al.'s [62] 2009 report on the CRP difference between obese and non-obese subjects by the rs1205 genotypes $\left.\left(P_{\text {interaction }}=0.02\right) ; E\right)$ Luetragoon et al.'s [67] 2017 report on the CRP difference between smokers and nonsmokers by CRP 1800947 genotypes; F) Shin et al.'s [68] 2007 report on the CRP difference (mg/dL) between smokers and nonsmokers by CRP rs1800796 genotypes. * Except where noted. 

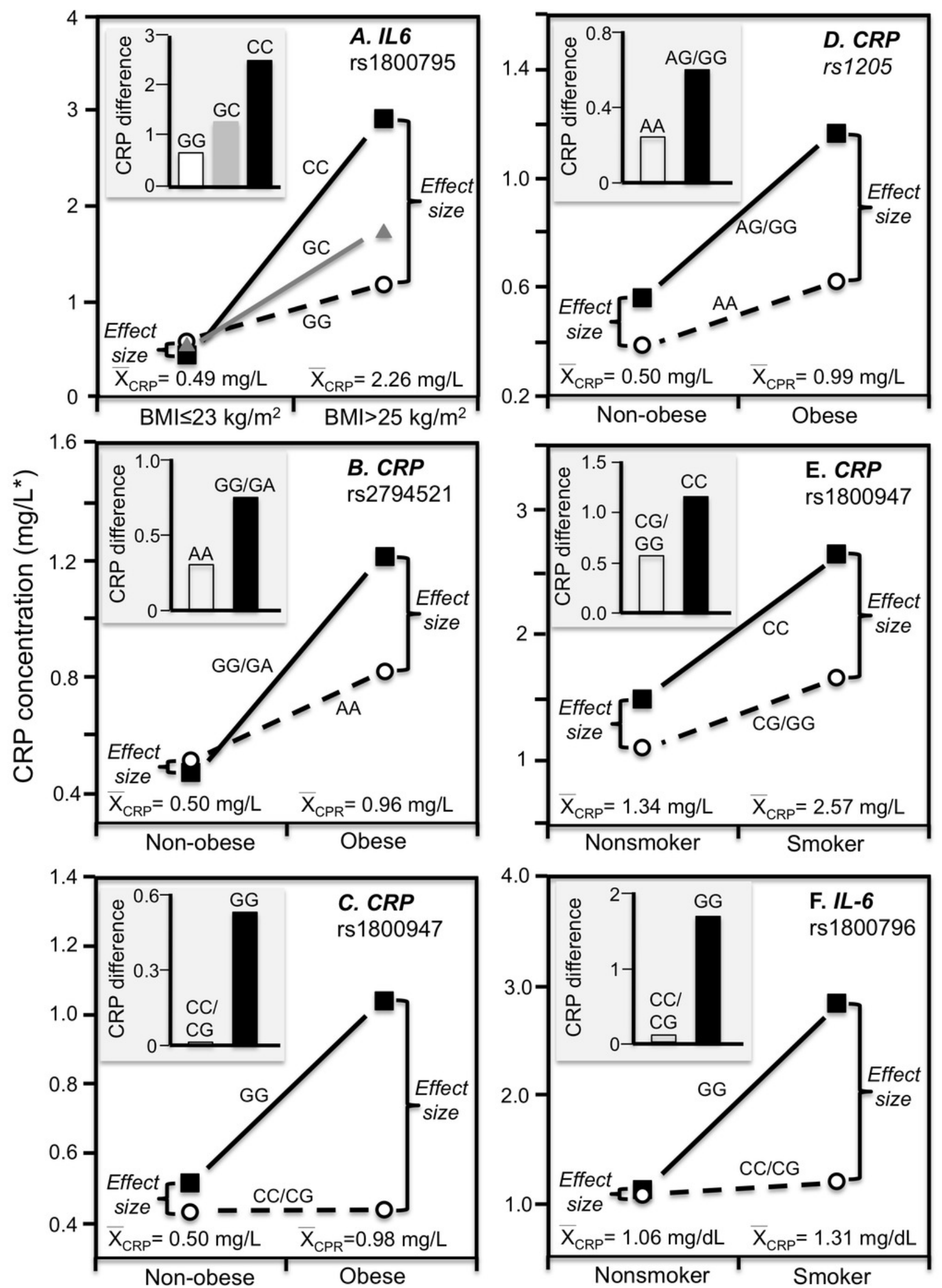


\section{Figure 5}

Precision medicine perspective of genotype-specific CRP differences (histogram inserts) vs. quantile-dependent expressivity perspective (line graphs).

Precision medicine perspective of genotype-specific CRP differences (histogram inserts) vs. quantile-dependent expressivity perspective (line graphs showing larger genetic effect size when average CRP concentrations were high) for the data presented in: A) Gander et al.'s [69] 2004 report on the CRP difference between smokers and nonsmokers by CRP rs1800629; B) Brull et al.'s [70] 2003 reported on the effect of 48-hour military endurance exercise on CRP concentrations by rs1130864 genotypes; C) Keramet et al.'s [72] 2017 report on the affect of monounsaturated fat intake on CRP concentrations by APOA2 rs5082 genotypes; D) Carvalho-Wells et al.'s [73] 2012 report on the effect of a high fat diet by APOE isoform; E) Gomez-Delgado et al.'s [74] 2015 report on the affect of a lowfat diet by CLOCK rs4580704 genotypes; F) Zee and Ridker's [75] report on the CRP difference between men experiencing vs. not experiencing their first arterial thrombosis during 8.6 year follow-up by CRP rs1800947 genotypes. 

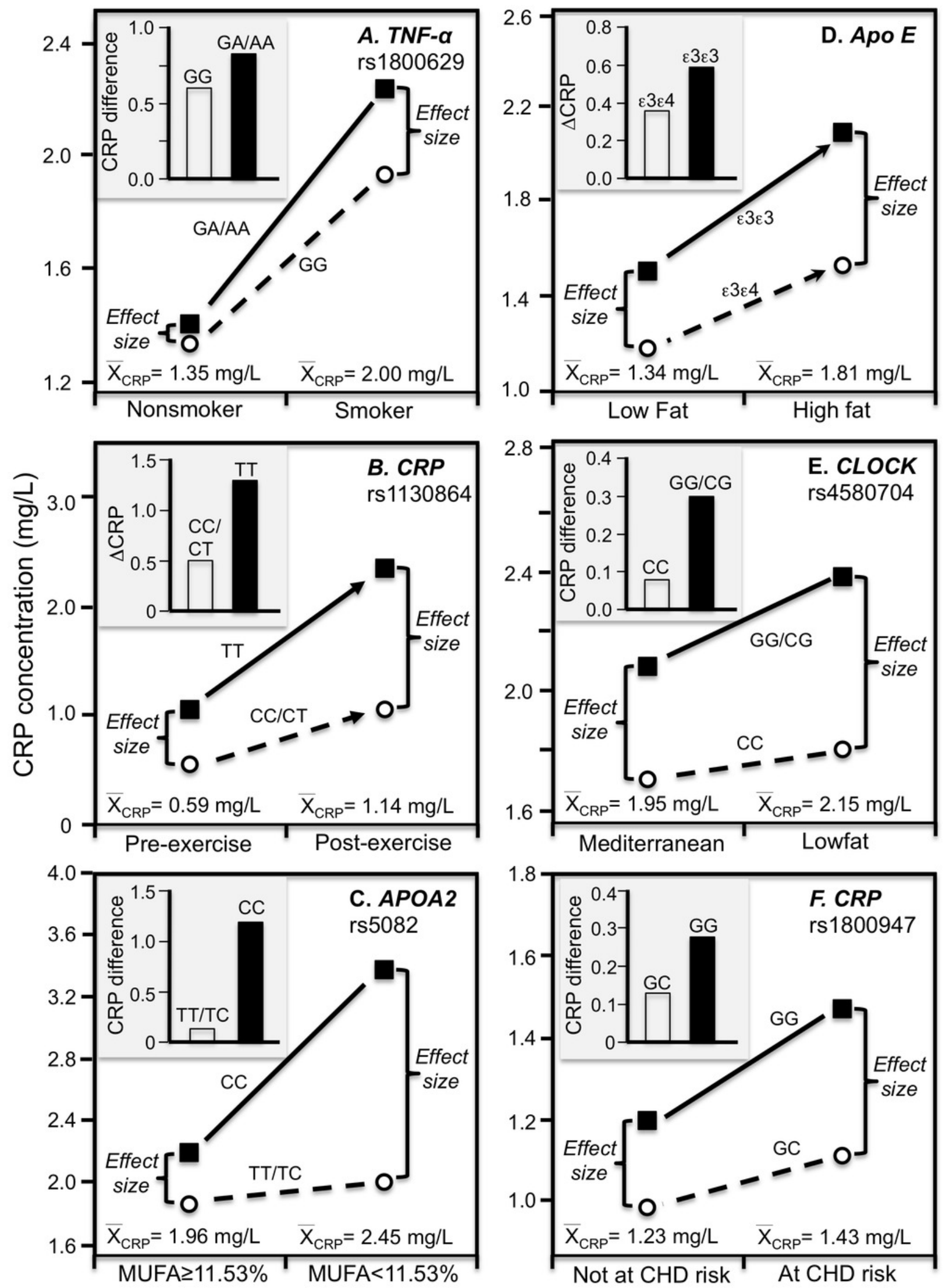


\section{Figure 6}

Precision medicine perspective of genotype-specific CRP differences (histogram inserts) vs. quantile-dependent expressivity perspective (line graphs).

Figure 6. Precision medicine perspective of genotype-specific CRP differences (histogram inserts) vs. quantile-dependent expressivity perspective (line graphs showing larger genetic effect size when average CRP concentrations were high) for the data presented in: A) Kovacs et al. [76] 2005 reported on the effect of myocardial infarction by CRP rs3091244 genotypes cross-sectionally; B) Qi et al.'s [80] 2007 report on the effect of T2DM by interleukin-6 receptor (IL6R) rs8192284 genotypes ( $P_{\text {interaction }}=0.03$ ); C) Libra et al.'s [81] 2006 report on the CRP difference between T2DM with (PAD+) and without (PAD-) peripheral arterial disease by IL-6 G(-174)C rs1800795 genotypes; D) Wypasek et al. [87] 2012 reported on the effects of coronary artery bypass grafting (CABG) surgery on CRP by fibrinogen beta-chain (FGB) -148C>T genotypes (rs1800787); E) Wypasek et al. [88] 2010 reported on the effects of CABG surgery on CRP by -174G>C IL-6 (rs1800795) genotypes; F) Mathew et al. [89] 2007 report on the effects of CABG with cardiopulmonary bypass by CRP +1059G >C ( $r s 1800947)$ genotypes. * Except where noted. 

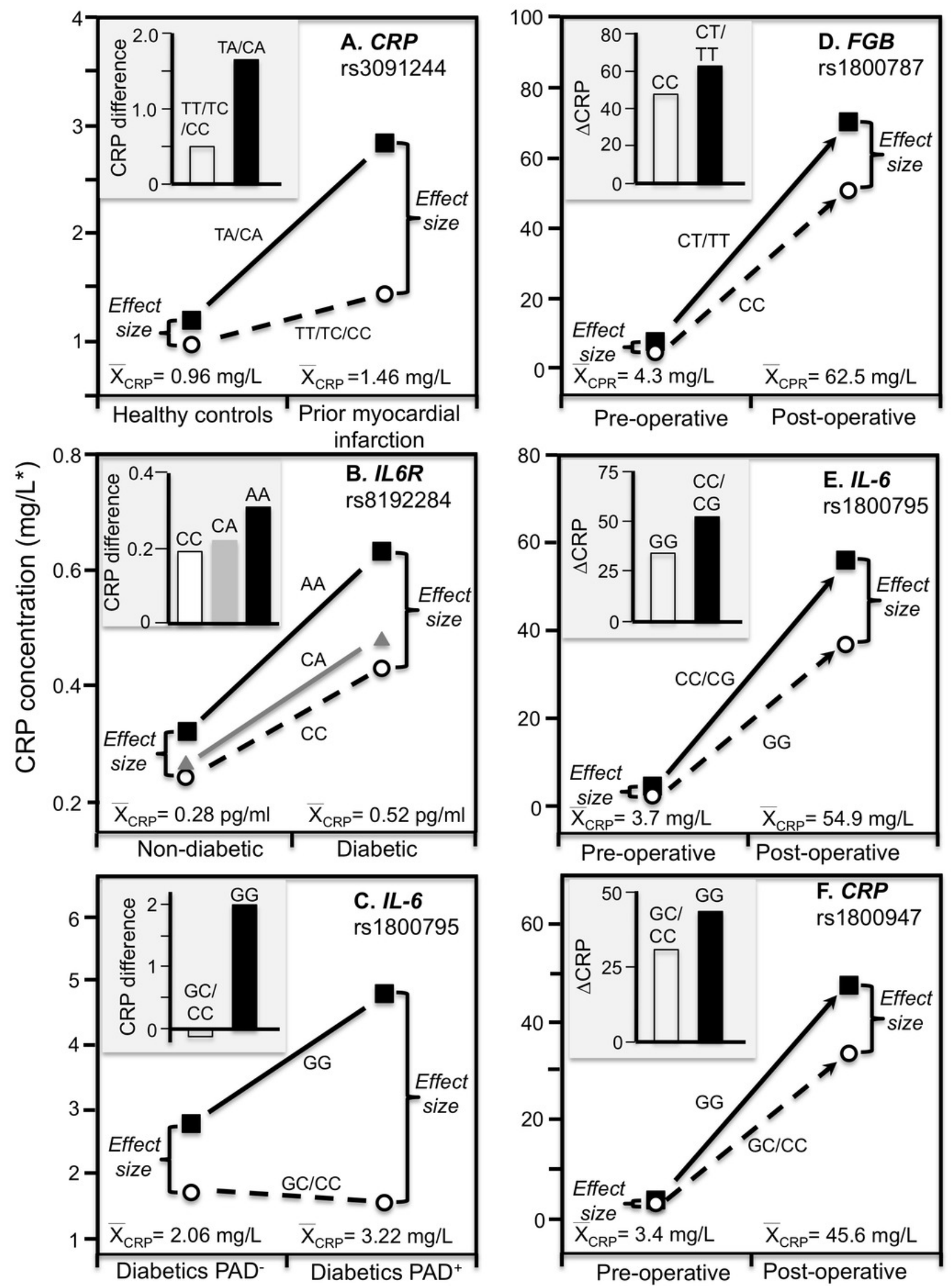


\section{Figure 7}

Precision medicine perspective of genotype-specific CRP differences (histogram inserts) vs. quantile-dependent expressivity perspective (line graphs).

Precision medicine perspective of genotype-specific CRP differences (histogram inserts) vs. quantile-dependent expressivity perspective (line graphs showing larger genetic effect size when average CRP concentrations were high) for the data presented in: A) Suk Danil et al. [42] 2006 report on the effect of acute coronary syndrome by CRP rs3091244 genotypes; B) Suk Danil et al. [42] 2006 report on the effect of acute coronary syndrome by CRP rs1800947 genotypes; and C) Suk Danil et al. [42] 2006 report on the effect of acute coronary syndrome by CRP rs1205 genotypes; D) Kovacs et al's [76] 2005 report on the effect of myocardial infarction (MI) by CRP rs3091244 genotypes longitudinally; E) Mölkänen et al. [93] 2010 reported on the effect of Staphylococcus aureus bacteremia by rs3091244 genotypes; F) Ammitzboll et al. [7] 2014 report on the effect of early chronic rheumatoid arthritis by CRP rs1205. 

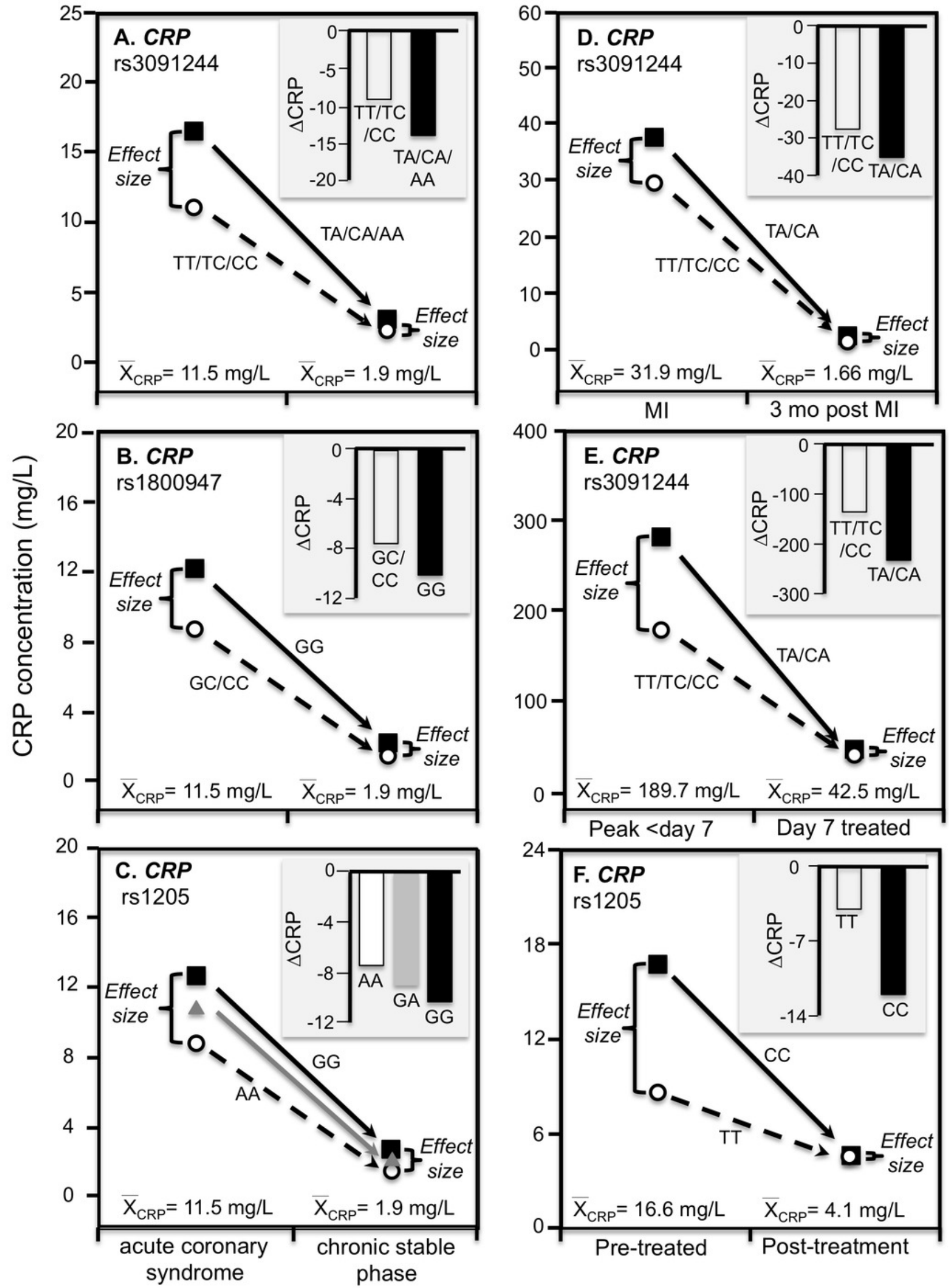


\section{Figure 8}

Precision medicine perspective of genotype-specific CRP differences (histogram inserts) vs. quantile-dependent expressivity perspective (line graphs).

Figure 8. Precision medicine perspective of genotype-specific CRP differences (histogram inserts) vs. quantile-dependent expressivity perspective (line graphs showing larger genetic effect size when average CRP concentrations were high) for the data presented in: A) Wielińska et al. [8] 2020 report on the effect of anti-TNF treatment by RANK rs8086340 genotypes; B) Wielińska et al.'s [8] 2020 report on the effect of anti-TNF treatment by RANKL rs7325635 genotypes; C) Vatay et al's [10] 2003 report on the CRP difference between active phase inflammatory bowel disease and healthy controls by tumor necrosis factor alpha (TNFa) G-308A (rs1800629) promoter polymorphism; D) Xu et al.'s [9] 2020 report on the effect of etanercept treatment in Ankylosing spondylitis patients by CRP rs3091244 genotypes; E) Liaquat et al. [95] on the effect of idiopathic dilated cardiomyopathy by TNF- $\alpha$ (rs1800629) -308G > A genotypes; F) Liaquat et al. [95] on the effect of idiopathic dilated cardiomyopathy by IL-6 rs1800795 (-174 G>C) genotypes. 

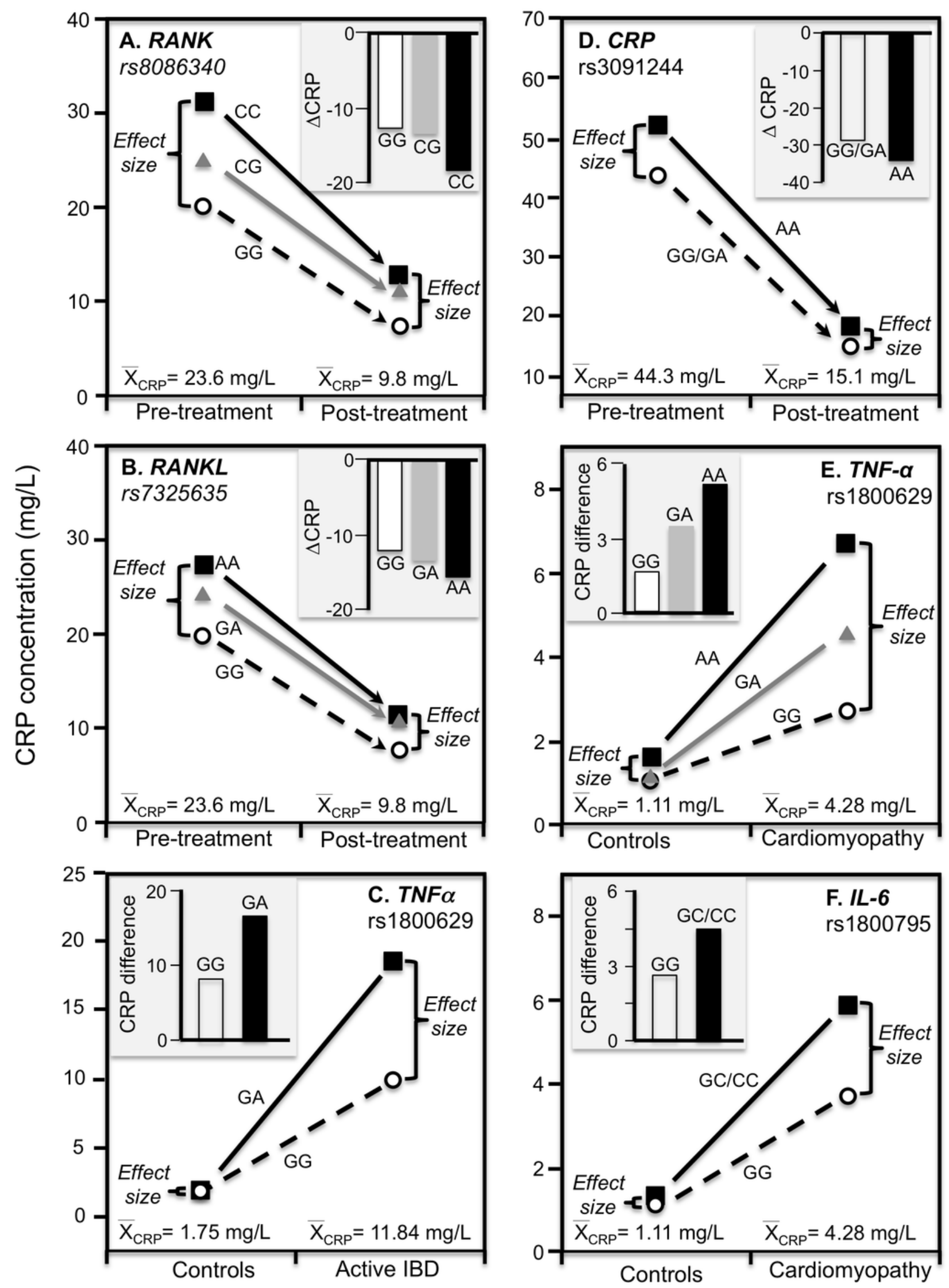


\section{Figure 9}

Precision medicine perspective of genotype-specific CRP differences (histogram inserts) vs. quantile-dependent expressivity perspective (line graph)

Figure 9. Precision medicine perspective of genotype-specific CRP differences (histogram inserts) vs. quantile-dependent expressivity perspective (line graphs showing larger genetic effect size when average CRP concentrations were high) for the data presented in Kim et al.'s [96] 2014 report on the effect of Kawasaki disease by CRP promoter rs12068753 genotypes. 


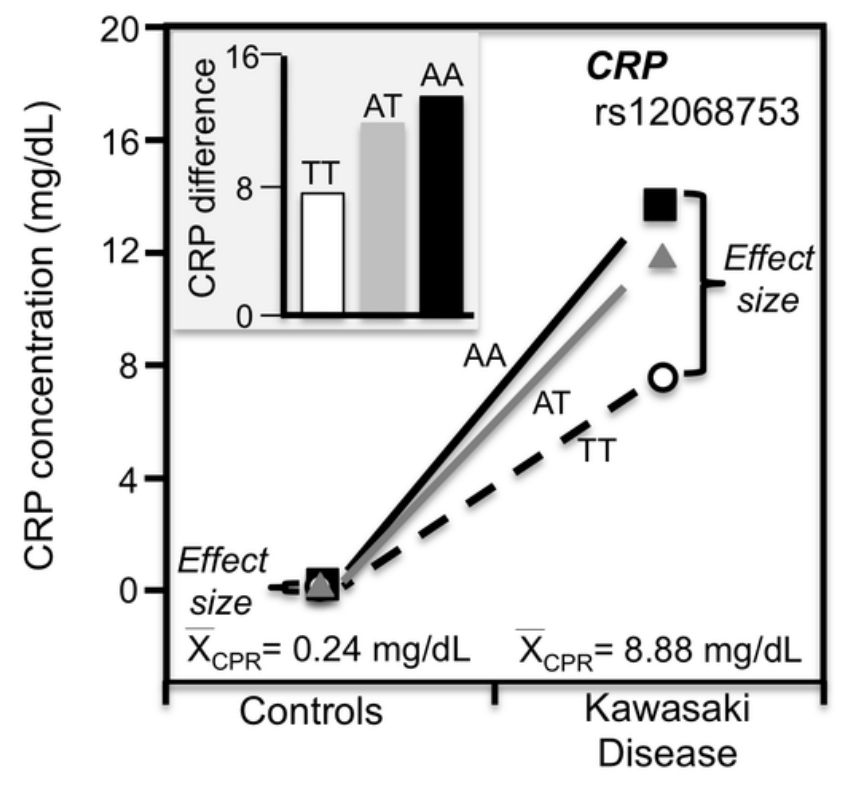

